\title{
Proximal Imaging of Changes in Photochemical Reflectance Index in Leaves Based on Using Pulses of Green-Yellow Light
}

\author{
Vladimir Sukhov ${ }^{1, *}\left(\mathbb{C}\right.$, Ekaterina Sukhova ${ }^{1} \oplus$, Andrey Khlopkov ${ }^{1}$, Lyubov Yudina ${ }^{1} \oplus$, Anastasiia Ryabkova ${ }^{1}$, \\ Alexander Telnykh ${ }^{2}$, Ekaterina Sergeeva ${ }^{2}$, Vladimir Vodeneev ${ }^{1}\left(\mathbb{1}\right.$ and Ilya Turchin ${ }^{2}$ (I) \\ 1 Department of Biophysics, N.I. Lobachevsky State University of Nizhny Novgorod, \\ 603950 Nizhny Novgorod, Russia; n.catherine@inbox.ru (E.S.); anbion@yandex.ru (A.K.); \\ lyubovsurova@mail.ru (L.Y.); nastay2903@bk.ru (A.R.); v.vodeneev@mail.ru (V.V.) \\ 2 Institute of Applied Physics of the Russian Academy of Sciences, 603155 Nizhny Novgorod, Russia; \\ telnykha@yahoo.com (A.T.); sea_nnov@yahoo.com (E.S.); ilya340@mail.ru (I.T.) \\ * Correspondence: vssuh@mail.ru; Tel.: +7-909-292-8653
}

check for updates

Citation: Sukhov, V.; Sukhova, E.; Khlopkov, A.; Yudina, L.; Ryabkova, A.; Telnykh, A.; Sergeeva, E.;

Vodeneev, V.; Turchin, I. Proximal Imaging of Changes in Photochemical Reflectance Index in Leaves Based on Using Pulses of Green-Yellow Light. Remote Sens. 2021, 13, 1762. https:// doi.org/10.3390/rs13091762

Academic Editor: Frédéric Cointault

Received: 1 April 2021

Accepted: 29 April 2021

Published: 1 May 2021

Publisher's Note: MDPI stays neutral with regard to jurisdictional claims in published maps and institutional affiliations.

Copyright: (c) 2021 by the authors. Licensee MDPI, Basel, Switzerland. This article is an open access article distributed under the terms and conditions of the Creative Commons Attribution (CC BY) license (https:// creativecommons.org/licenses/by/ $4.0 /)$

\begin{abstract}
Plants are affected by numerous environmental factors that influence their physiological processes and productivity. Early revealing of their action based on measuring spectra of reflected light and calculating reflectance indices is an important stage in the protection of agricultural plants. Photochemical reflectance index (PRI) is a widely used parameter related to photosynthetic changes in plants under action of stressors. We developed a new system for proximal imaging of PRI based on using short pulses of measuring light detected simultaneously in green $(530 \mathrm{~nm})$ and yellow $(570 \mathrm{~nm})$ spectral bands. The system has several advances compared to those reported in literature. Active light illumination and subtraction of the ambient light allow for PRI measurements without periodic calibrations. Short duration of measuring pulses $(18 \mathrm{~ms})$ minimizes their influence on plants. Measurements in two spectral bands operated by separate cameras with aligned fields of visualization allow one to exclude mechanically switchable parts like filter wheels thus minimizing acquisition time and increasing durability of the setup. Absolute values of PRI and light-induced changes in PRI $(\triangle P R I)$ in pea leaves and changes of these parameters under action of light with different intensities, water shortage, and heating have been investigated using the developed setup. Changes in $\triangle \mathrm{PRI}$ are shown to be more robust than the changes in the absolute value of PRI which is in a good agreement with our previous studies. Values of PRI and, especially, $\triangle P R I$ are strongly linearly related to the energy-dependent component of the non-photochemical quenching and can be potentially used for estimation of this component. Additionally, we demonstrate that the developed system can also measure fast changes in PRI (hundreds of milliseconds and seconds) under leaf illumination by the pulsed green-yellow measuring light. Thus, the developed system of proximal PRI imaging can be used for PRI measurements (including fast changes in PRI) and estimation of stressors-induced photosynthetic changes.
\end{abstract}

Keywords: photochemical reflectance index; PRI; photosynthetic proximal sensing; non-photochemical quenching; pulsed light; water shortage; heating; plants

\section{Introduction}

Remote and proximal sensing which are based on sensors being far and close to the objects, respectively, are among the most important methods of estimation of plant morphology and physiological processes in modern agriculture. Multi- and hyperspectral imaging is the widely-used basis of the sensing [1] allowing for quick measurements of changes in spectra of reflected light without physical contact with the object which are strongly related to numerous physiological processes including photosynthesis [2-5], water exchange [6,7], changes in contents of pigments [8-13], emission of plant volatiles (e.g., isoprene emission [14,15]), electrical signaling [16-18], responses on damages by phytopathogens [19-21], primary production [22], etc. Early revealing of plant changes 
under actions of abiotic and biotic stressors is an important task of multi- and hyperspectral imaging aimed, particularly, at minimizing the plant damage and at protecting the crop.

Calculation of reflectance indices based on measurements of the intensities of reflected light at specific wavelengths is a conventional way of analysis of multi- and hyperspectral data. The analysis can be based on the previously proposed reflectance indices including normalized difference vegetation index (NDVI) [23,24], water index (WI) [6,7] and normalized difference water index (NDWI) [25], near-infrared reflectance of terrestrial vegetation $\left(\mathrm{NIR}_{\mathrm{V}}\right)$ [22], and many others. Alternatively, the analysis can be based on complex investigation of all possible reflectance indices [15,26-31] which opens ways to search for new reflectance indices in plants.

Noted reflectance indices mainly show relatively slow processes including slow photosynthetic changes. For example, NDVI is dependent on chlorophyll content and shows the photosynthetically active biomass in plants $[23,24]$. Changes in the index require long time intervals (at least, several days). As a result, NDVI usage for early revealing actions of stressors is limited. It means that proximal sensing of stressors-induced changes in plants requires using reflectance indices which can be changed quickly under actions of environmental factors.

A photochemical reflectance index (PRI), which was proposed by Gamon et al. (1992) [32], is the perspective optical parameter for early revealing photosynthetic changes [33-35]. Traditionally, Equation (1) is used for PRI calculation [33-35]; however, using modified spectral changes can be also effective for revealing photosynthetic changes (e.g., [36]):

$$
P R I=\frac{R_{531}-R_{570}}{R_{531}+R_{570}},
$$

where $R_{531}$ and $R_{570}$ are the intensities of reflected light at 531 and $570 \mathrm{~nm}$, respectively. It was shown [32] that $R_{531}$ can be strongly decreased under action of stressors (e.g., excess light) that induces decrease of PRI.

Fast changes in PRI can be formed for minutes and, even, seconds [32,37-41]. The changes are caused by acidification of lumens accompanied with activity of photosynthetic electron transport chain [33-35]. It means that PRI should be strongly related to photosynthetic parameters including the energy-dependent component of the non-photochemical quenching (the fast-relaxing component, $\mathrm{NPQ}_{\mathrm{F}}$ [42]) because this component is induced by lumen acidification $[43,44]$. Earlier, we showed that absolute values of PRI and, especially, light-induced changes in PRI $(\triangle \mathrm{PRI})$ are strongly related to $\mathrm{NPQ}_{\mathrm{F}}[16,41,45]$. Potential mechanisms of the changes are related to the $\mathrm{pH}$-dependent de-epoxidation of violaxanthin to zeaxanthin via antheraxanthin [32,37,46,47] and (or) chloroplast shrinkage [38] and subsequent induction of light scattering at 530-546 nm [40,41]. Also, there are long-term changes in PRI [13,48-51] based on modifications of carotenoid/chlorophyll pigment ratios and the total xanthophyll pigment pool size.

However, using PRI to reveal early photosynthetic stress changes can be restricted by number of factors including the necessary of calibration of a measurement system and influence of the illumination conditions which can significantly vary in field or greenhouse with combined light (artificial light + sunlight). Modern systems use constant artificial illumination or sunlight and require continuous (or periodic) application of reflectance standard (e.g., see PRI imaging system proposed in papers [52,53]). Our meta-analysis [35] shows that using artificial light can increase correlation between PRI and photosynthetic parameters in comparison to the correlations under sunlight.

Earlier, we developed the method of proximal PRI sensing [41] based on using short measuring pulses of green-yellow light (GYL) and calculating differences between intensities of reflected light with GYL (background light and measuring green-yellow light) and without GYL (background light only). We showed experimentally that using the proposed illumination method excludes the influence of background light and provides PRI measurement without continuous application of reflectance standard [41]. The obtained results demonstrated that the measured PRI and, especially, $\triangle \mathrm{PRI}$ were strongly related 
to $\mathrm{NPQ}_{\mathrm{F}}$. Thus, the reported method has high potential in the development of new tools for proximal sensing of PRI in leaves and canopy without calibration procedure under changeable ambient light conditions. However, durations of GYL pulses were $30 \mathrm{~s}$ in [41] that could potentially influence PRI because a fast component of PRI is formed within several seconds [38]. The use of short GYL pulses (much less than $1 \mathrm{~s}$ ) shouldn't affect PRI and can be an important step of further development of the method.

The aim of the present work is the development of a new system for proximal imaging of PRI based on measuring back reflected GYL using short pulses of artificial light and accounting for ambient light. The design of the setup allowed to avoid using mechanically switchable parts (which are used, e.g., in $[52,53]$ ) in order to increase the speed of data acquisition and the system durability. The system capabilities have been tested in the preliminary studies including revealing photosynthetic changes induced by light with different intensities, water shortage and heating in plants in laboratory experiments on pea seedlings.

\section{Materials and Methods}

\subsection{Plant Materials, Water Shortage and Heating}

We used 2-to-3-week-old seedlings of pea (Pisum sativum L., cultivar Albumen) in the investigation. Plants were cultivated in a sand substrate in growth room under $16 / 8 \mathrm{~h}$ (light/dark) photoperiod at $24{ }^{\circ} \mathrm{C}$. Plants were irrigated every 2 days.

Water shortage was induced by absence of irrigation for 5 days in accordance with [31,45]; the irrigation was not changed in control plants. PRI, $\mathrm{NPQ}_{\mathrm{F}}$, and relative water content in plant leaves were measured every day of the water shortage. The relative water content was calculated on the basis of measuring fresh and dry weights of leaves. The dry weight was measured after $2 \mathrm{~h}$ of high temperature action (about $100{ }^{\circ} \mathrm{C}$ ) in a TV-20-PZ-K thermostat (Kasimov Instrument Plant, Kasimov, Russia).

Heating was induced by action of increased temperature $\left(46^{\circ} \mathrm{C}\right)$ for $30 \mathrm{~min}$ in the TV-20-PZ-K thermostat. Control plants were not heated. PRI and NPQ ${ }_{\mathrm{F}}$ were measured in $1 \mathrm{~h}$ and 1 day after heating in accordance with [31,45].

\subsection{Description of the Developed System for Proximal PRI Imaging}

Figure 1 shows the schematic of the developed system of proximal PRI imaging based on using measuring artificial light. The system included several light-emitting diodes (LEDs) LXML-PX02-0000 (Lumileds, Schipol, The Netherlands) which form spatially homogeneous illumination of a plant object by GYL. Figure S1 shows emission spectra of LEDs; the main part of the spectra was in the green-yellow spectral range corresponding to the detection in green and yellow bands of back reflected light. The LEDs had approximately equal intensities of light at 530 and $570 \mathrm{~nm}$ enabling measurements in both bands with the CCDs having the same exposure time.

Green-yellow light reflected back from the plant object is delivered to beamsplitter FF552-Di02 (Semrock, Rochester, NY, USA), which reflects light with wavelengths below $550 \mathrm{~nm}$ (green reflected light, GRL) and transmits light with wavelengths exceeding $550 \mathrm{~nm}$ (yellow reflected light, YRL) (Figure S1). Further, GRL is transmitted through the bandpass filter FF01-530/11 (Semrock) with $530 \mathrm{~nm}$ center wavelength and $11 \mathrm{~nm}$ bandwidth (Figure S1) proving fine spectral selection of the GRL. GRL image is captured by the first 12-bit CCD camera CGN-B013-U (Mightex, Toronto, Ontario, Canada) with external trigger. YRL transmitted through the bandpass filter FF01-575/15 (Semrock) with $575 \mathrm{~nm}$ center wavelength and $15 \mathrm{~nm}$ bandwidth (Figure S1) is detected by the second identical CCD camera with the same exposure and amplification. Both cameras are adjusted for the same imaging area; however, a minor mismatch in the overlapping of green and yellow images takes place which is compensated by the numerical algorithm described below. Pulsed operation of the LEDs, cameras exposures and their synchronization is controlled by ARDUINO UNO (Arduino, Turin, Italy). 


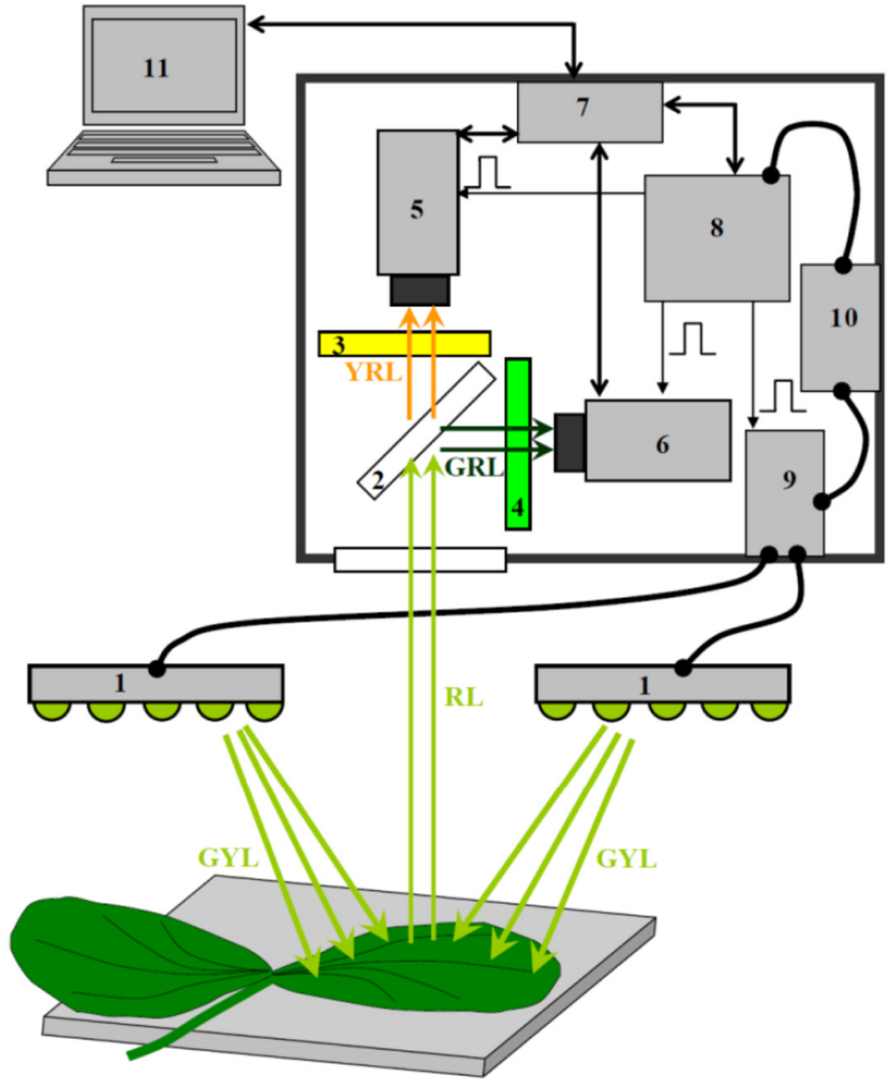

(a)

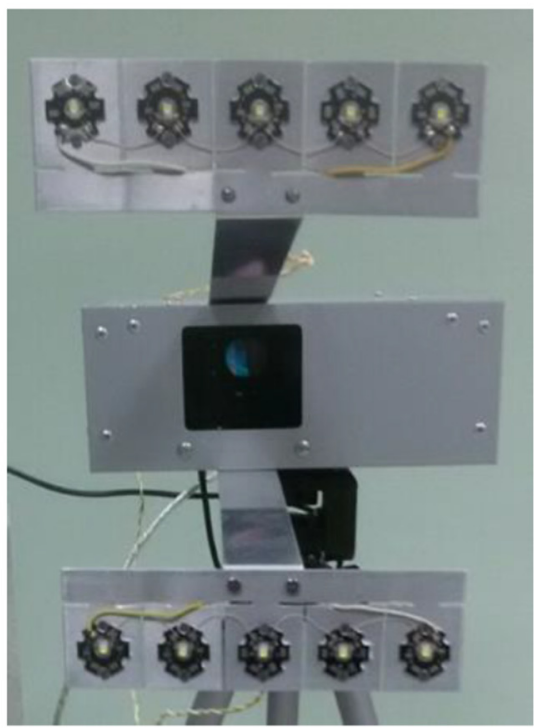

(b)

Figure 1. The schema (a) and photo (b) of the developed system for photochemical reflectance measurements. The system includes light-emitting diodes (LEDs) (1), beamsplitter (2), bandpass filters for yellow (3) and green (4) light CCD cameras with objective lenses (5, 6), USB hub (7), ARDUINO UNO (8), LEDs current source (9), power supply (10), and a laptop (11). GYL is the green-yellow measuring light. RL is the reflected light. GRL and YRL are green and yellow RLs, respectively.

There are two regimes of measuring PRI (Figure 2). The first (main) regime of the measuring cycle (Figure 2a) included short-term illuminations of plants by GYL (pulse duration was $18 \mathrm{~ms}$ and measurements lasted from 3rd to 13th millisecond) which should weakly influence PRI because the measuring pulse is significantly shorter than the durations of all potential mechanisms of the index changes. For example, the duration of the fast changes in the light scattering at $530-546 \mathrm{~nm}$, which is probably the fastest mechanism of PRI changes, is about $1 \mathrm{~s}$ in pea leaves [40]. The second regime (Figure 2b) provides plant illumination by GYL from hundreds of milliseconds to seconds. It was used for analysis of fast changes in PRI with durations less than several seconds [38].

The sequence and duration of GYL pulses and CCD triggering for selected regime (Figure 2) is stored in ARDUINO memory and runs in cyclic mode. A set of four images (dark image at $530 \mathrm{~nm}$, dark image at $570 \mathrm{~nm}$, measuring image at $530 \mathrm{~nm}$, and measuring image at $570 \mathrm{~nm}$ ) was the result of the measuring cycle. The software of the system written in $\mathrm{C}++$ programming language calculated differences between the measuring and the dark images. After that, minor mismatch in the overlapping of green and yellow images were compensated and the images at $530 \mathrm{~nm}$ and at $570 \mathrm{~nm}$ were used for calculation of the PRI spatial distribution in accordance with Equation (1); PRI was calculated for each pixel of the image. 
dark images

images under LEDs on

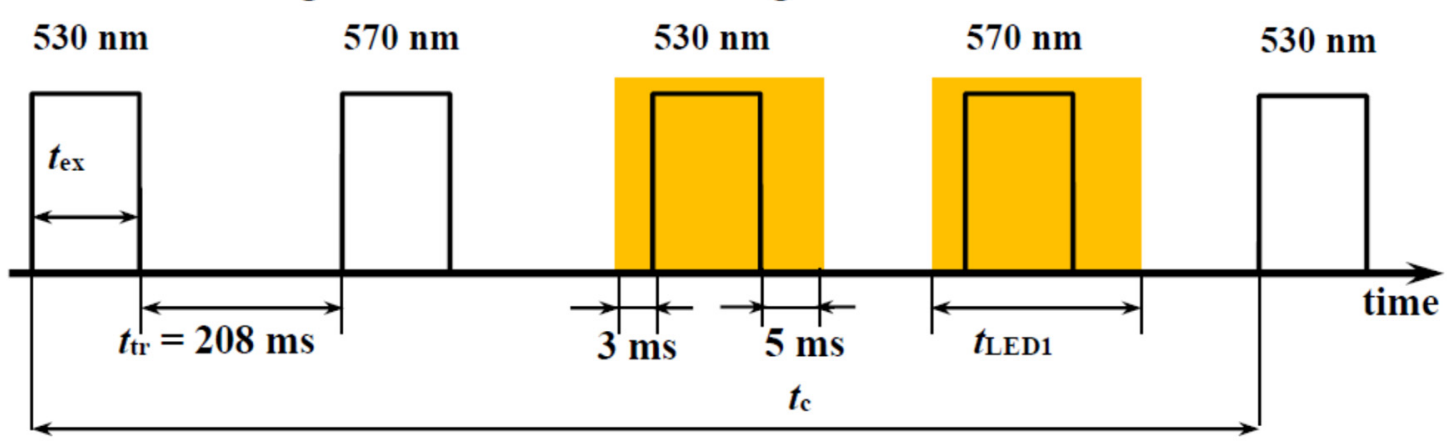

(a)

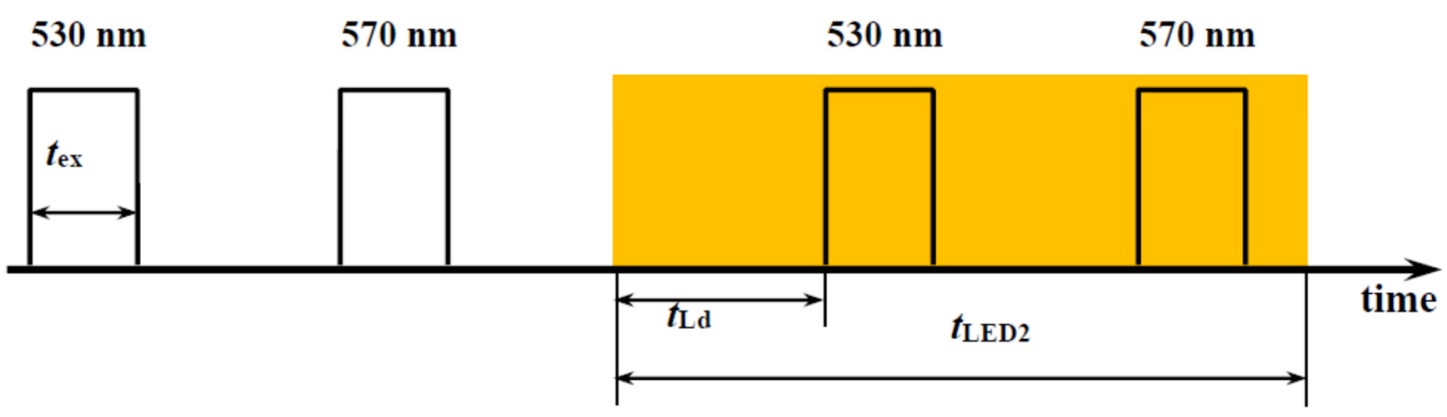

(b)

Figure 2. Duty cycles of PRI imaging system in two regimes: minimum illumination by GYL (a), and variable illumination by GYL (b). Cycle duration of the first regime, $t c$, is $872 \mathrm{~ms}$, exposure time, $t_{\mathrm{ex}}$, is set to $10 \mathrm{~ms}$ for all CCD frames, the delay between frames, $t_{\mathrm{tr}}$, is set to $208 \mathrm{~ms}$ for data transferring, the delay time between LEDs on and starting frame capture is set to $3 \mathrm{~ms}$ to exclude transition processes of LEDs during frame exposure, LEDs pulse duration in the first regime, $t_{\mathrm{LED} 1}$, is set to $18 \mathrm{~ms}$, in the second regime LEDs pulse duration, $t_{\mathrm{LED} 2}$, is changes by varying the delay between LEDs on and frame capture in the second regime, $t_{\mathrm{Ld}}$. Dark images are measured under background illumination; measuring images are measured under GYL illumination and the background illumination. In our paper, the background illumination included the measuring light and actinic light, which were used for measurements of chlorophyll fluorescence (see Section 2.3 for details).

The numerical algorithm of compensation of the mismatch between two images obtained from both CCDs is based on construction of the coordinate transformation matrix for $570 \mathrm{~nm}$ images. This matrix transforms coordinates of pixels in the $570 \mathrm{~nm}$ images to correspond the pixels in $530 \mathrm{~nm}$ images. Estimation of transformation matrix coefficients is based on the calibration procedure. This procedure consists of the following steps: (1) measurement of a simple calibration picture (the chessboard with black and white cells), (2) finding an array of key points on the calibration images, (3) creation of transformation matrix using linear regression. The calibration procedure is embedded in the software of the system and repeated only if the focal distances has been changed.

Additional calibration was used to compensate spatial inhomogeneities of the transferring function caused by imperfection of objective lenses and inhomogeneities of the illumination light (about $20 \%$ ), and also difference in sensitivity of $530 / 11 \mathrm{~nm}$ and $570 / 15$ spectral channels (about $5 \%$ ). This calibration was provided using a white calibration standard and corresponding amplitude coefficients for each pixel on each image were calculated and stored in the memory of a software. The white calibration standard was also used for checking of weak influencing the ambient light on measured PRIs. It was revealed that difference between PRIs measured in the white sheet under the background light (white fluorescent lamp) and PRIs measured in the sheet without the background light 
was about $1.6 \%$. Additionally, turning on ambient illumination slightly increased standard deviation of PRI measurement from 0.7 to $0.9(\mathrm{SD} \times 1000)$. Thus, the background light weakly influenced value of PRI.

\subsection{Simultaneous Measurements of Fast Relaxing Component of Non-Photochemical Quenching} and PRI

The system of pulse-amplitude-modulation (PAM) imaging Open FluorCam FC 800O/1010 (Photon Systems Instruments, Drasov, Czech Republic) was used for measuring $\mathrm{NPQ}_{\mathrm{F}}$ in pea leaves. Four pea seedlings were simultaneously measured. The leaves and stems were kept at fixed positions in same plane (Figure 3).

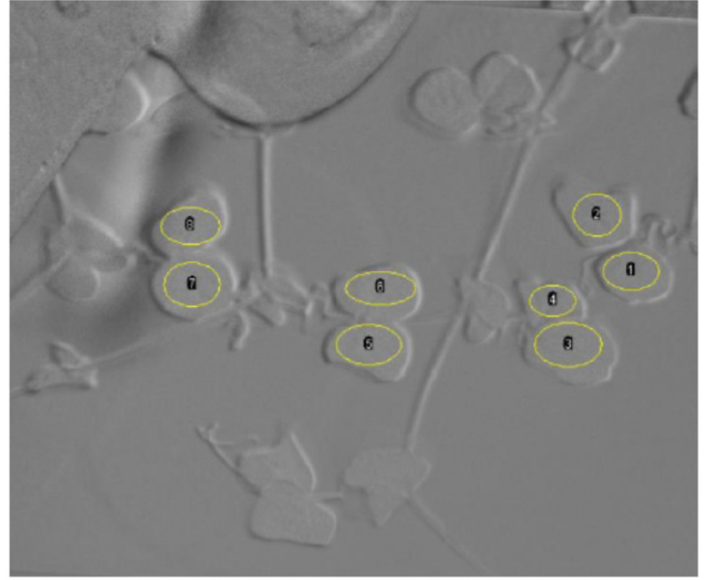

(a)

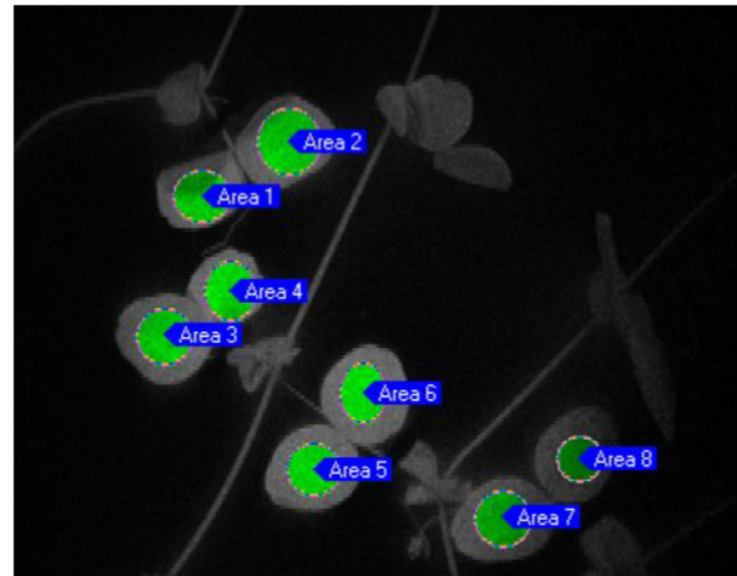

(b)

Figure 3. Example of localization of ROIs at measurement of photochemical reflectance index (PRI) (a) and chlorophyll fluorescence $(\mathbf{b})$. Four pea seedlings were simultaneously measured, and two ROIs placed on pair leaflets were used for each seedling.

The maximum yield of fluorescence (Fm) was measured at the saturation pulse (SP, $4000 \mu \mathrm{mol} \mathrm{m}{ }^{-2} \mathrm{~s}^{-1}$, cold white light, $6500 \mathrm{~K}$ ) after dark adaptation for $15 \mathrm{~min}$. After that, SPs were generated every minute and the corresponding maximum yields of fluorescence under light and dark conditions (Fm's) were measured.

There were two regimes of the NPQF measurement. Light dependences of NPQF were measured with using the following sequence of the light conditions: periodical SPS and red actinic light $(\mathrm{AL}, 617 \mathrm{~nm})$ with $70 \mu \mathrm{mol} \mathrm{m} \mathrm{m}^{-2} \mathrm{~s}^{-1}$ intensity for $5 \mathrm{~min}$, periodical SPs without AL for $5 \mathrm{~min}$, periodical SPs and AL with $140 \mu \mathrm{mol} \mathrm{m}^{-2} \mathrm{~s}^{-1}$ intensity for $5 \mathrm{~min}$, periodical SPs without AL for $5 \mathrm{~min}$, periodical SPs and AL with $210 \mu \mathrm{mol} \mathrm{m} \mathrm{m}^{-2} \mathrm{~s}^{-1}$ intensity for $5 \mathrm{~min}$, periodical SPs without AL for $5 \mathrm{~min}$, periodical SPs and AL with $280 \mu \mathrm{mol} \mathrm{m}{ }^{-2} \mathrm{~s}^{-1}$ intensity for $5 \mathrm{~min}$, periodical SPs without AL for $5 \mathrm{~min}$. Influence of the water shortage and high temperature on NPQF were analyzed using periodical SPs and AL with $280 \mu \mathrm{mol} \mathrm{m}{ }^{-2} \mathrm{~s}^{-1}$ intensity for $10 \mathrm{~min}$ and following periodical SPs without AL for $5 \mathrm{~min}$. Seedlings were eliminated from the experiment after each measurement. Equation (2) was used for calculation of $\mathrm{NPQ}_{\mathrm{F}}[41,42]$ :

$$
\mathrm{NPQ}_{\mathrm{F}}=\frac{\mathrm{Fm}}{\mathrm{Fm}^{\prime 0}}-\frac{\mathrm{Fm}}{\mathrm{Fm}^{\prime}}
$$

where $\mathrm{Fm}^{\prime 0}$ and $\mathrm{Fm}^{\prime S}$ are the $\mathrm{Fm}^{\prime}$ before the termination of illumination and for 5 min after that, respectively.

PRI measurements were performed simultaneously with the measurements of the chlorophyll fluorescence and the pulses of GYL $(18 \mathrm{~ms})$ were generated every $5 \mathrm{~s}$. Angle between optical axes of the proximal PRI imaging system and the investigated leaves was 
about $45^{\circ}$; distance from LEDs to leaves was about $50 \mathrm{~cm}$. The illumination intensity of GYL (during the pulse) measured at the leaf surface by a Thorlabs PM100D optical power meter (Thorlabs Inc., Newton, MA, USA) with the S120VC sensor (200-1100 nm) was $23 \mu \mathrm{mol} \mathrm{m}{ }^{-2} \mathrm{~s}^{-1}$. Figure 3 shows ROIs, which were used for analysis. There were two ROIs for each plant (eight ROIs for four seedlings in each measurement). ROIs for $\mathrm{NPQ}_{\mathrm{F}}$ measurements corresponded to ROIs for PRI measurements. Parameters of $\mathrm{NPQ}_{\mathrm{F}}$ in the ROIs were analyzed by software of the Open FluorCam FC 800-O/1010. Parameters of PRI in the ROIs were analyzed by ImageJ. $\triangle$ PRIs were calculated as difference between PRI before termination of illumination and PRI before termination of initial dark adaptation.

\subsection{Measurements of Changes in PRI Induced by Short-Term Illuminations by GYL}

The measurements of changes in PRI induced by short-term illumination by GYL were like other PRI measurements, but there were no measurements of chlorophyll fluorescence. Leaves were illuminated by GYL after dark adaptation; actinic light, measuring light and saturation pulses were absent. Angle between optical axis of the proximal PRI imaging system and investigated leaves was about $45^{\circ}$; distance from LEDs to leaves was about $30 \mathrm{~cm}$. The illumination intensity of GYL (during the pulse) measured by Thorlabs PM100D optical power meter (Thorlabs Inc.) at the leaf surface was $57 \mu \mathrm{mol} \mathrm{m}{ }^{-2} \mathrm{~s}^{-1}$.

The changes in PRI were calculated as difference between PRI after the specific duration of illumination by GYL and PRI at $18 \mathrm{~ms}$ GYL action. The duration of illuminations by GYL was varied from $300 \mathrm{~ms}$ to $3200 \mathrm{~ms}$.

\subsection{Statistics}

A separate set of pea seedlings of pea was used for each experiment. The number of repetitions was varied from 8 to 16 in different experiments; specific numbers of repetitions (n) are shown in figures. Mean values, standard errors (SEs), scatter plots, linear regression equations and determination coefficients are shown in figures. A Student's $t$-test was used to estimate significance of differences.

\section{Results}

\subsection{Relations of PRI and $\triangle P R I$ to $N P Q_{F}$ under Different Intensities of Actinic Light}

Figure 4 shows dependences of $\mathrm{NPQ}_{\mathrm{F}}, \mathrm{PRI}$ and $\triangle \mathrm{PRI}$ on intensity of the actinic light in pea leaves. It was shown that increase of the AL intensity stimulated forming the fast component of the non-photochemical quenching (Figure 4a). The significantly increased $\mathrm{NPQ}_{\mathrm{F}}$ was shown under light intensities equaling to $140 \mu \mathrm{mol} \mathrm{m} \mathrm{m}^{-2} \mathrm{~s}^{-1}$ and more. In contrast, $\mathrm{NPQ}_{\mathrm{F}}$ under the $70 \mu \mathrm{mol} \mathrm{m}{ }^{-2} \mathrm{~s}^{-1} \mathrm{AL}$ intensity was about zero.

Absolute value of PRI decreased with the AL intensity increase, but significant changes in PRI were only observed under light intensities equal to 210 and $280 \mu \mathrm{mol} \mathrm{m}{ }^{-2} \mathrm{~s}^{-1}$ (Figure $4 \mathrm{~b})$. Dependence of light-induced changes in PRI $(\triangle \mathrm{PRI})$ on intensity of illumination by AL was similar to the dependence of absolute values of PRI (Figure 4c); however, significant changes were observed at all investigated light intensities (from $70 \mu \mathrm{mol} \mathrm{m}{ }^{-2} \mathrm{~s}^{-1}$ to $280 \mu \mathrm{mol} \mathrm{m}^{-2} \mathrm{~s}^{-1}$ ). It should be noted that light dependence of $\mathrm{NPQ}_{\mathrm{F}}$ was similar to the dependences of PRI and $\triangle \mathrm{PRI}$ under light intensities equaling to 140,210 and $280 \mu \mathrm{mol} \mathrm{m}{ }^{-2} \mathrm{~s}^{-1}$, but changes in photochemical reflectance index were also observed under $70 \mu \mathrm{mol} \mathrm{m}{ }^{-2} \mathrm{~s}^{-1}$ intensity of the actinic light.

Figure 5 shows scatter plots between averaged $\mathrm{PRI}$ and $\mathrm{NPQ}_{\mathrm{F}}$ and between averaged $\triangle \mathrm{PRI}$ and $\mathrm{NPQ}_{\mathrm{F}}$. Both PRI and $\triangle \mathrm{PRI}$ were linearly related to $\mathrm{NPQ}_{\mathrm{F}}$ (the determination coefficient $\left(\mathrm{R}^{2}\right)$ exceeded 0.8 ). It should be noted that the first point of dependence (under zero AL illumination) falls out of the linear trend of PRI and $\triangle \mathrm{PRI}$ on $\mathrm{NPQ}_{\mathrm{F}}$. We separately analyzed scatter plots between PRI and $\mathrm{NPQ}_{\mathrm{F}}$ and between $\triangle \mathrm{PRI}$ and $\mathrm{NPQ}_{\mathrm{F}}$ without the first point (Figure S2). Excluding data under zero AL intensity strongly increased efficiency of the linear relation of PRI and $\triangle P R I$ to $\mathrm{NPQ}_{\mathrm{F}}\left(\mathrm{R}^{2}\right.$ exceeded 0.94). The result showed the light-induced changes of PRI included a component which was not related to $\mathrm{NPQ}_{\mathrm{F}}$. Considering regression equation for $\triangle \mathrm{PRI}$ and $\mathrm{NPQ}_{\mathrm{F}}$ (Figure $\mathrm{S} 2 \mathrm{~b}$ ), it could be supposed 
that the magnitude of this component was about 4 relative units $(\Delta \mathrm{PRI} \times 1000)$. Figure $\mathrm{S} 3$ shows scatter plots between individual values of the parameters which are principally similar to the scatter plots on basis of averaged values.

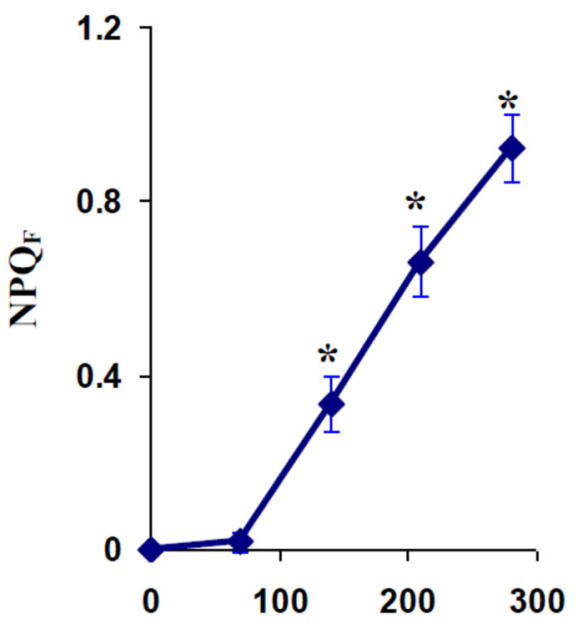

AL intensity, $\mu \mathrm{mol} \mathrm{m} \mathrm{m}^{-2}$

(a)

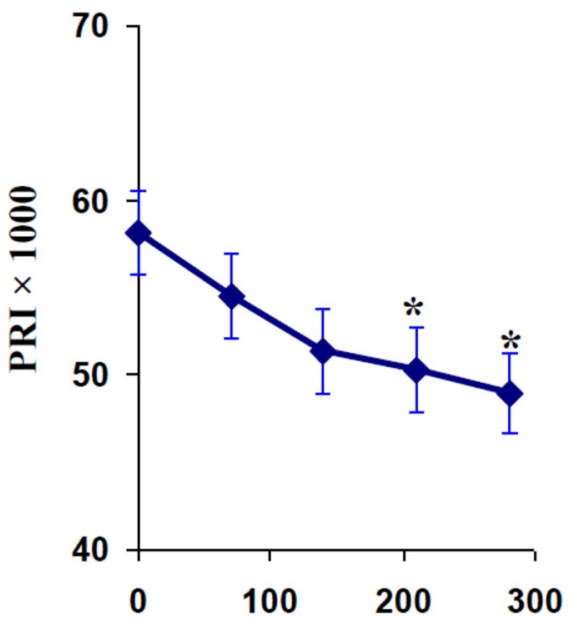

AL intensity, $\mu \mathrm{mol} \mathrm{m} \mathbf{m}^{-2} \mathrm{~s}^{-1}$

(b)

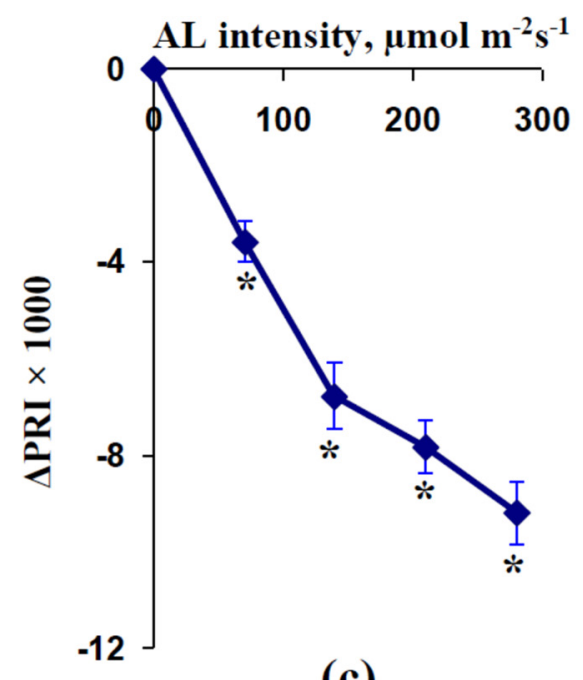

(c)

Figure 4. Dependences of the energy-dependent component of the non-photochemical quenching of fluorescence $\left(\mathrm{NPQ}_{\mathrm{F}}\right)(\mathbf{a})$, the absolute value of PRI (b), and its change $(\triangle \mathrm{PRI})(\mathbf{c})$ in leaves of pea seedlings on intensity of the actinic light $(\mathrm{AL}, 617 \mathrm{~nm})(n=16)$. Measurements were initiated after 15 min dark adaptation. Durations of AL actions with different intensities were 5 min followed by 5 min dark interval after each illumination. The absolute value of PRI was measured before termination of illumination. $\triangle \mathrm{PRI}$ was measured as the difference between PRI measured before termination of illumination with specific AL intensity and the initial PRI measured before initiation of the first illumination. * indicates that the value of the parameter significantly differed $(p<0.05)$ from the value before initiation of the first illumination. $n$ is number of repetitions. Bars show standard errors. 


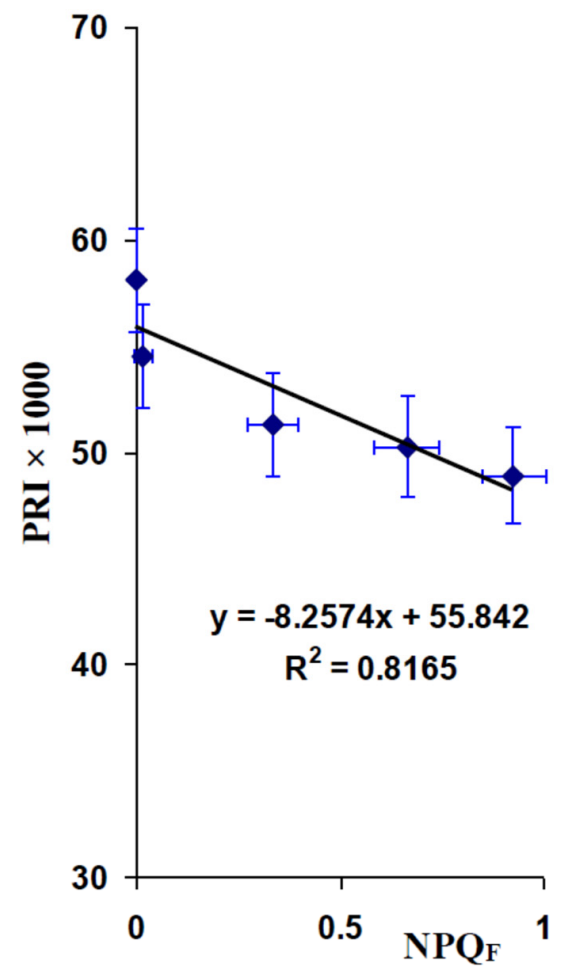

(a)

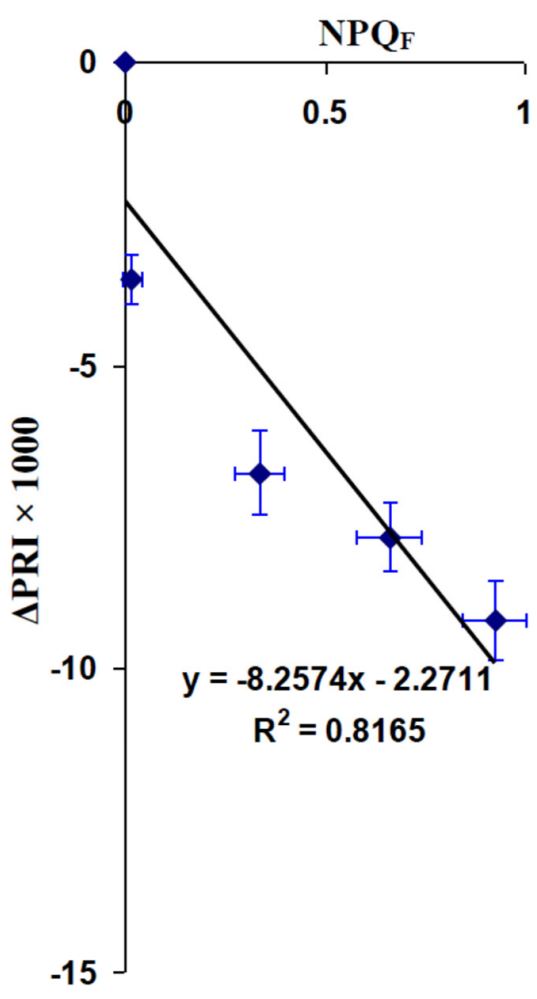

(b)

Figure 5. Scatter plots and linear regression trends between $\mathrm{NPQ}_{\mathrm{F}}$ and $\mathrm{PRI}(\mathbf{a})$ and between $\mathrm{NPQ}_{\mathrm{F}}$ and $\triangle P R I(b)$ in experiments with actions of ALs with different intensities. $K_{\mathrm{I}}=-8.2574$ and $\mathrm{K} \Delta_{\mathrm{I}}=-8.2574$ are linear regression coefficients in the plots (a) and (b), respectively. Average values of parameters and standard errors from Figure 3 were used. $R^{2}$ is the determination coefficient. Bars show standard errors.

\subsection{Relations of PRI and $\triangle P R I$ to $N P Q_{F}$ under Water Shortage}

It was shown (Figure S3) that absence of irrigation induced fast decrease of the relative water content in pea leaves. The decrease was significant in 3rd and 4th days of the water shortage. The maximal magnitude of the decrease (4th day of the water shortage) was about $10 \%$.

Figure 6 shows changes in NPQF, PRI, and $\triangle P R I$ during the course of the water shortage. Magnitudes of $\mathrm{NPQ}_{\mathrm{F}}$ were significantly increased for all days of the water shortage. Maximal increasing $\mathrm{NPQ}_{\mathrm{F}}$ was observed in 3rd and 4th days under absence of the irrigation. Changes in absolute values of PRI and $\triangle P R I$ were similar to the changes in $\mathrm{NPQ}_{\mathrm{F}}$. PRI was significantly increased for all days of the water shortage excluding 4th day; $\triangle$ PRI was significantly decreased.

Figure 7 shows scatter plots between PRI and NPQ and between $\triangle P R I$ and $N_{P Q}$ under the water shortage. The scatter plots were calculated on the basis of averaged values of investigated parameters from Figure 6. It was shown that both PRI and $\triangle P R I$ were linearly related to $\mathrm{NPQ}_{\mathrm{F}}$, however, the dependences differed. $\triangle \mathrm{PRI}$ decreased with the increase of $\mathrm{NPQ}_{F}$; it was similar to the dependence under action of illumination with different light intensities. In contrast, absolute value of PRI increased with increase of $\mathrm{NPQ}_{\mathrm{F}}$. The effect was in a good accordance with the results of our previous study with the use of a spectrometer [45]. Figure S5 shows scatter plots between individual values of the parameters which are principally similar to the scatter plots on basis of averaged values (especially, for $\triangle \mathrm{PRI}$ and $\mathrm{NPQ}_{\mathrm{F}}$ ). The results showed that the irrigation absence decreased $\triangle \mathrm{PRI}$ and increased PRI; the last result could be related to changes in content of photosynthetic pigments. 


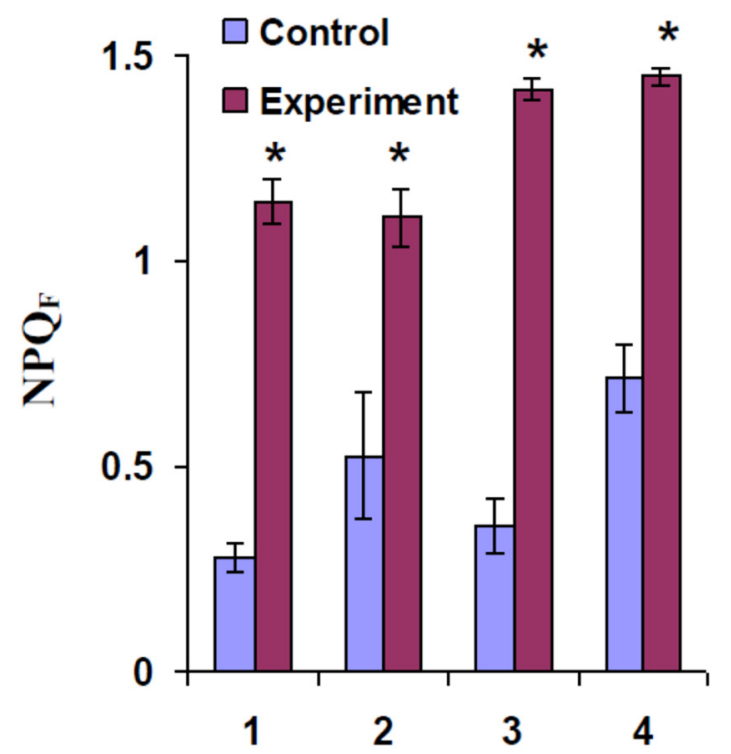

Duration of the water shortage, days

(a)

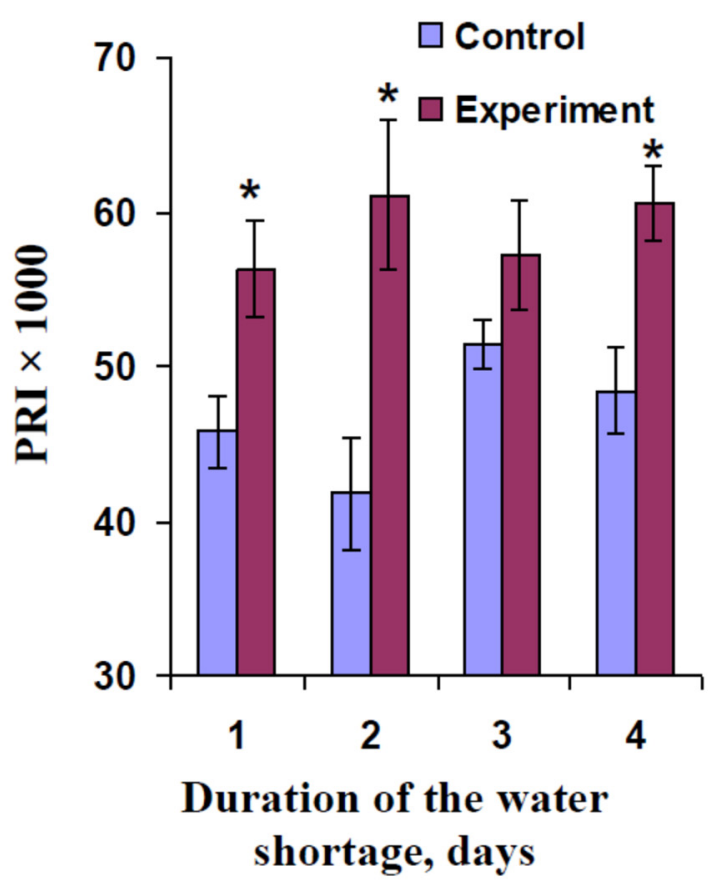

(b)

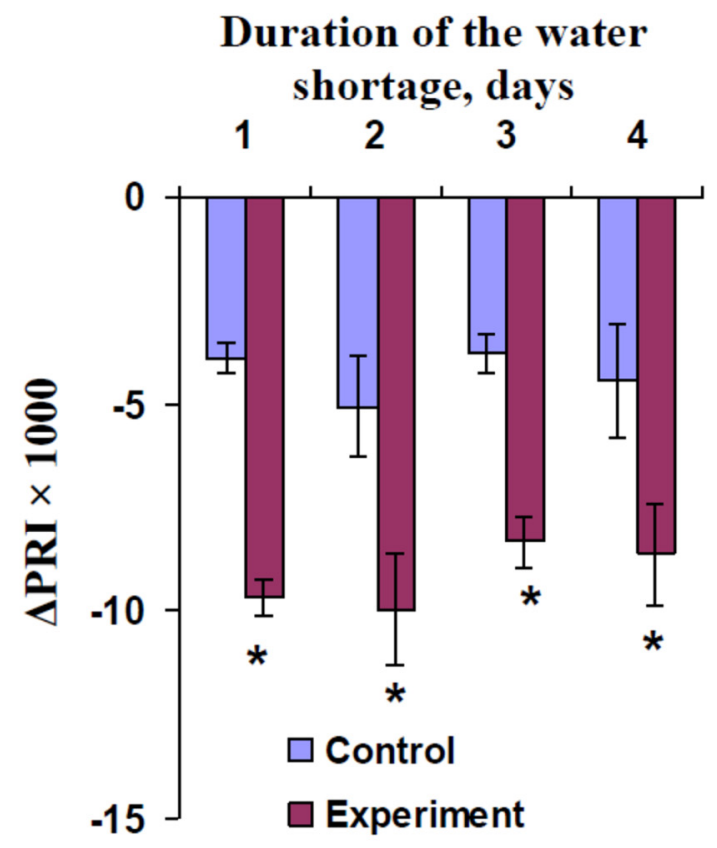

(c)

Figure 6. Dependences of the energy-dependent component of the non-photochemical quenching of fluorescence $\left(\mathrm{NPQ}_{\mathrm{F}}\right)$ (a), the absolute value of PRI (b), and its change $(\triangle \mathrm{PRI})(\mathbf{c})$ in leaves of pea seedlings on the duration of the water shortage $(n=12)$. Measurements were initiated after 15 min dark adaptation. Duration of AL action $\left(617 \mathrm{~nm}, 280 \mu \mathrm{mol} \mathrm{m}^{-2} \mathrm{~s}^{-1}\right)$ was $10 \mathrm{~min}$ followed by $5 \mathrm{~min}$ of dark interval. The absolute value of PRI was measured before termination of illumination. $\triangle \mathrm{PRI}$ was measured as difference between PRI measured before termination of the illumination, and the initial PRI measured before initiation of the illumination. The water shortage was induced by elimination of irrigation in experimental seedlings; control plants were irrigated. ${ }^{*}$ indicates that experimental and control parameters significantly differed $(p<0.05)$. $n$ is number of repetitions. Bars show standard errors. 


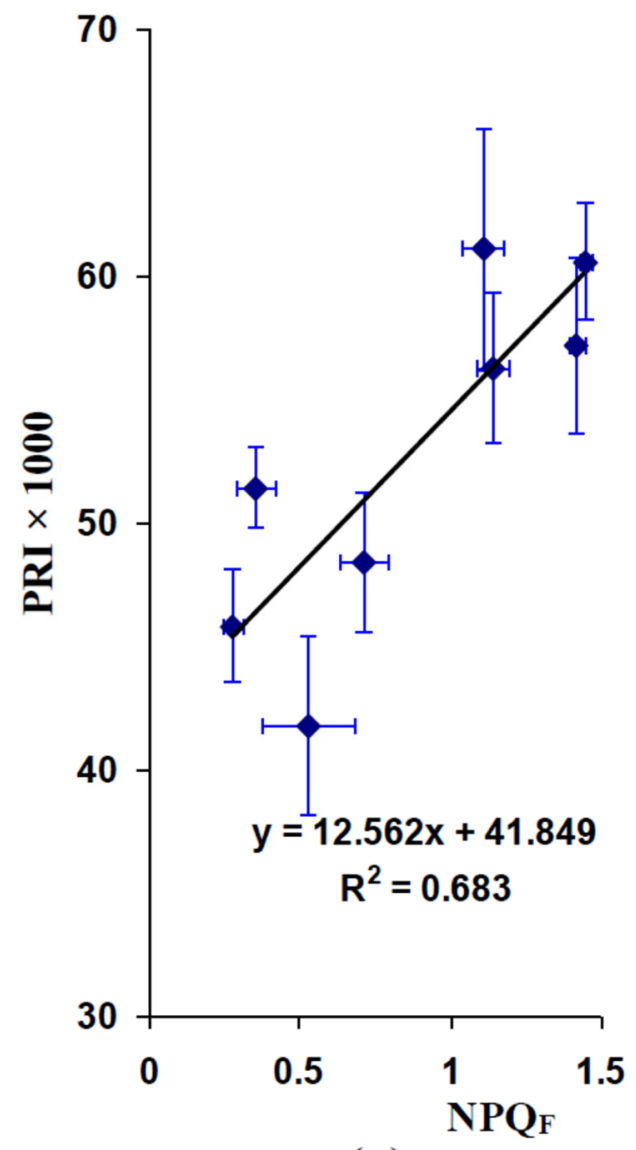

(a)

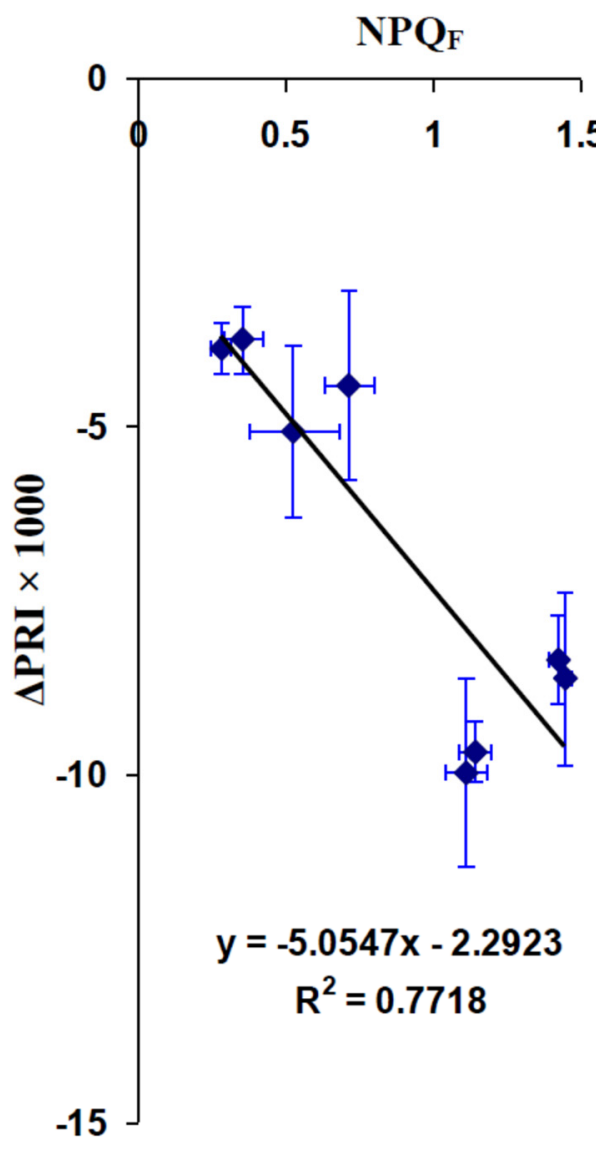

(b)

Figure 7. Scatter plots between $\mathrm{NPQ}_{\mathrm{F}}$ and PRI (a) and between $\mathrm{NPQ}_{\mathrm{F}}$ and $\triangle \mathrm{PRI}(\mathbf{b})$ in experiments with water shortage. $\mathrm{K}_{W}=12.562$ and $\mathrm{K} \Delta_{W}=-5.0547$ are linear regression coefficients in the plots (a) and (b), respectively. Average values of parameters and standard errors from Figure 6 were used. $\mathrm{R}^{2}$ is the determination coefficient. Bars show standard errors.

\subsection{Relations of PRI and $\triangle P R I$ to $N P Q_{F}$ after Heating}

Analysis of the heating influence on $\mathrm{NPQ}_{F}$, PRI, and $\triangle \mathrm{PRI}$ showed that the influence was weak (Figure 8). There were no significant changes in the energy-dependent component of the non-photochemical quenching and absolute value of photochemical reflectance index. Only weak tendencies of $\mathrm{NPQ}_{\mathrm{F}}$ and PRI increase were observed in $1 \mathrm{~h}$ after heating. $\triangle \mathrm{PRI}$ was significantly decreased in $1 \mathrm{~h}$ after the heating, but in 1 day after the heating it was the same as the control value. This result is in accordance with the result of our previous studies [45], which showed that the absolute value of PRI was weakly influenced by heating in pea leaves; in contrast, $\triangle \mathrm{PRI}$ significantly decreased in $1 \mathrm{~h}$ after action of the heating.

Figure 9 shows scatter plots between averaged PRI and $\mathrm{NPQ}_{\mathrm{F}}$ and between averaged $\triangle \mathrm{PRI}$ and $\mathrm{NPQ}_{\mathrm{F}}$ after the heating. The scatter plots were calculated on the basis of averaged values of investigated parameters from the Figure 8. It was shown that the relation between $\mathrm{PRI}$ and $\mathrm{NPQ}_{\mathrm{F}}$ was weak. In contrast, $\triangle \mathrm{PRI}$ was strongly linearly dependent on $\mathrm{NPQ}_{\mathrm{F}}$ $\left(\mathrm{R}^{2}\right.$ exceeded 0.88 ). Figure $\mathrm{S} 6$ shows scatter plots between individual values of the parameters. 


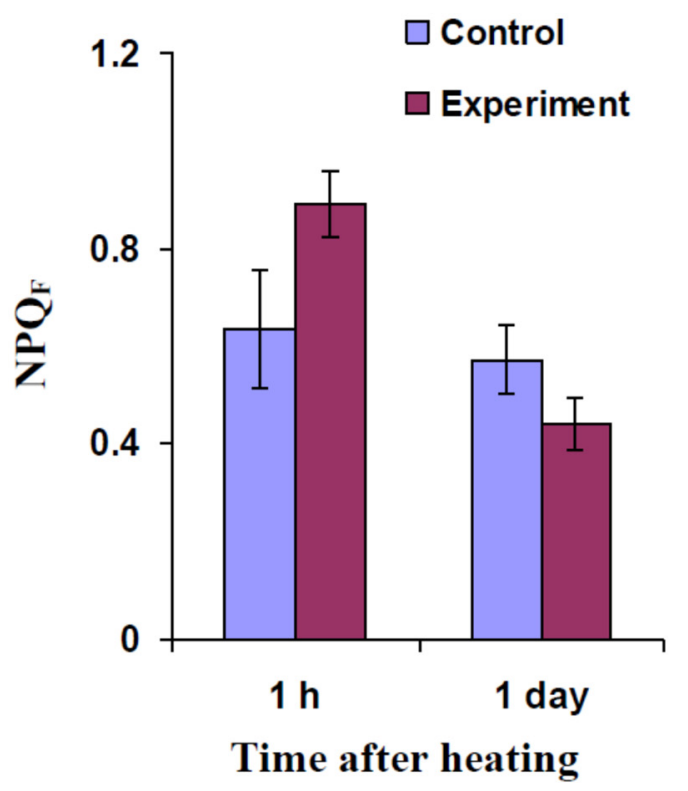

(a)

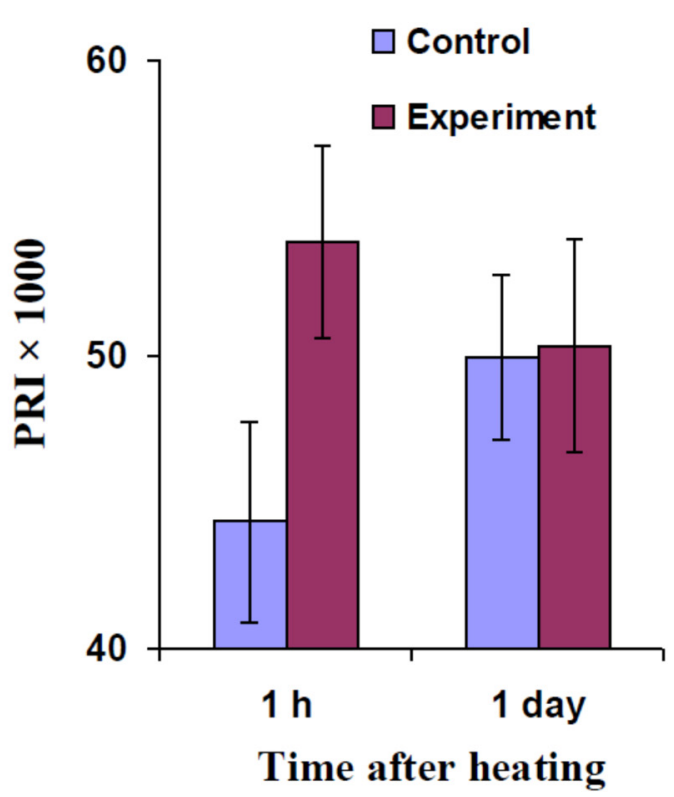

(b)

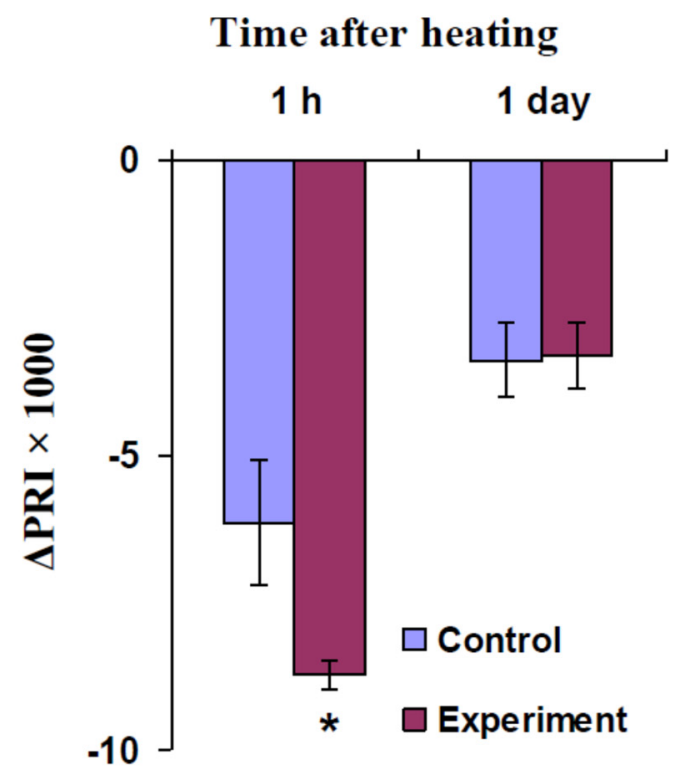

(c)

Figure 8. The energy-dependent component of the non-photochemical quenching of fluorescence (NPQ $\mathrm{N}_{\mathrm{F}}(\mathbf{a})$, the absolute value of PRI (b), and its change ( $\triangle \mathrm{PRI})(\mathbf{c})$ in leaves of pea seedlings in $1 \mathrm{~h}$ and 1 day after short-term heating $(n=12)$. Measurements were initiated after $15 \mathrm{~min}$ dark adaptation. Duration of AL action $\left(617 \mathrm{~nm}, 280 \mu \mathrm{mol} \mathrm{m}^{-2} \mathrm{~s}^{-1}\right)$ was $10 \mathrm{~min}$ followed by 5 min dark interval. The absolute value of PRI was measured before termination of illumination. $\triangle$ PRI was measured as difference between PRI measured before termination of the illumination, and the initial PRI measured before initiation of the illumination. The experimental seedlings were heated for $30 \mathrm{~min}$ at $46{ }^{\circ} \mathrm{C}$; control plants were not heated. * indicates that experimental and control parameters significantly differed $(p<0.05)$. $n$ is number of repetitions. Bars show standard errors. 


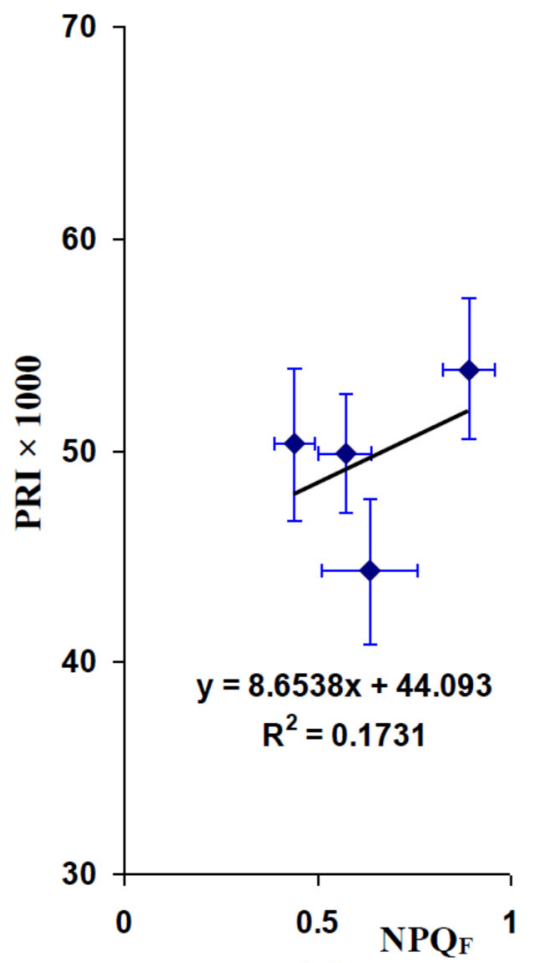

(a)

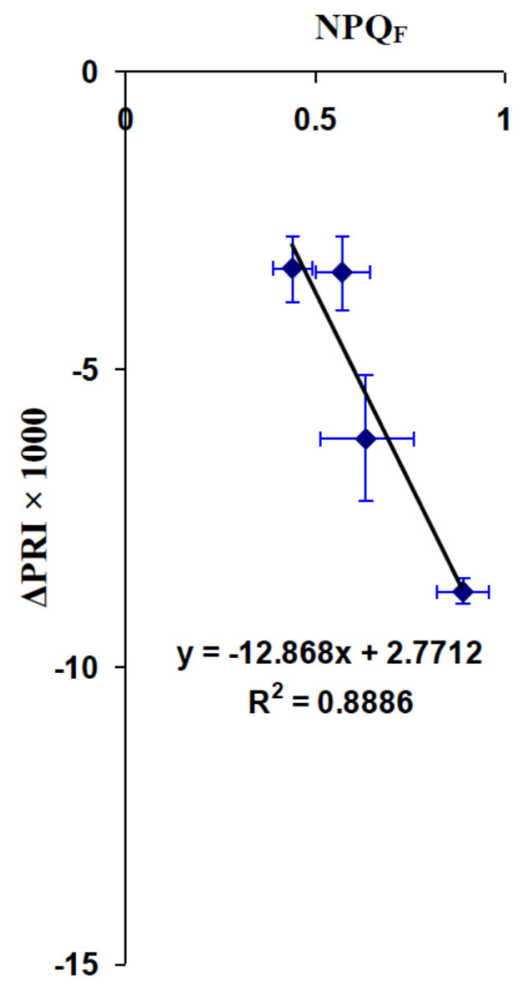

(b)

Figure 9. Scatter plots between $\mathrm{NPQ}_{\mathrm{F}}$ and PRI (a) and between $\mathrm{NPQ}_{\mathrm{F}}$ and $\triangle \mathrm{PRI}(\mathbf{b})$ in experiments with heating. $\mathrm{K}_{\mathrm{H}}=7.5327$ and $\mathrm{K} \Delta_{\mathrm{H}}=-12.868$ are linear regression coefficients in the plots (a) and (b), respectively. Average values of parameters and standard errors from Figure 8 were used. $R^{2}$ is the determination coefficient. Bars show standard errors.

\subsection{Total Relations of PRI and $\triangle P R I$}

Figure 10 shows scatter plots between PRI and $\mathrm{NPQ}_{\mathrm{F}}$ and between $\triangle \mathrm{PRI}$ and $\mathrm{NPQ}_{\mathrm{F}}$ based on all abovementioned results. The scatter plots were calculated based on averaged values of investigated parameters from the Figures 4,6 and 8. It was shown that relation of absolute PRI values to $\mathrm{NPQ}_{\mathrm{F}}$ was weak. In contrast, $\triangle \mathrm{PRI}$ strongly decreased with increase of $\mathrm{NPQ}_{\mathrm{F}}$. The dependence was linear $\left(\mathrm{R}^{2}\right.$ exceeded 0.68$)$ and was similar to the dependences of $\triangle \mathrm{PRIs}$ on $\mathrm{NPQ}_{\mathrm{F}}$ which were calculated by using spectrometer under illumination by light with different intensities [41] and under action of water shortage and heating [45]. Figure S7 shows scatter plots between individual values of the parameters which are principally similar to the scatter plots on basis of averaged values (at least, for $\triangle \mathrm{PRI}$ and $\mathrm{NPQ}_{\mathrm{F}}$ ).

\subsection{Changes in PRI Induced by Short-Term Illuminations by GYL}

Figure 11 shows changes in PRI induced by short-term illumination by green-yellow light. It was showed that GYL induced the first decrease of PRI (up to $700 \mathrm{~ms}$ ), partial recovery of PRI (1200-2200 ms), and the second PRI decrease (3200 ms). The result was in accordance with the paper by Evain et al. [38] which showed fast changes in PRI (within seconds). Also, it showed that the developed system can be applied for measuring the fast changes. 


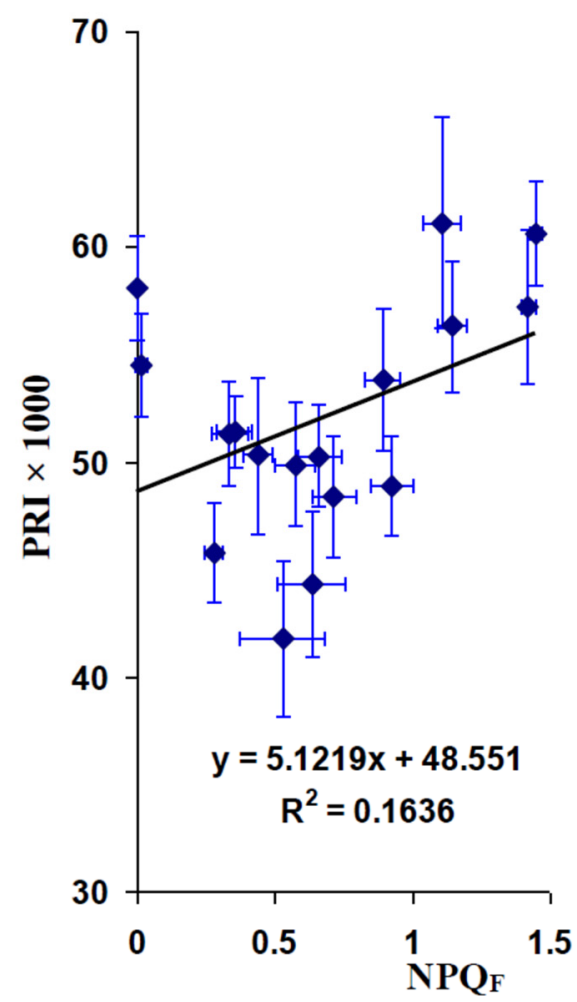

(a)

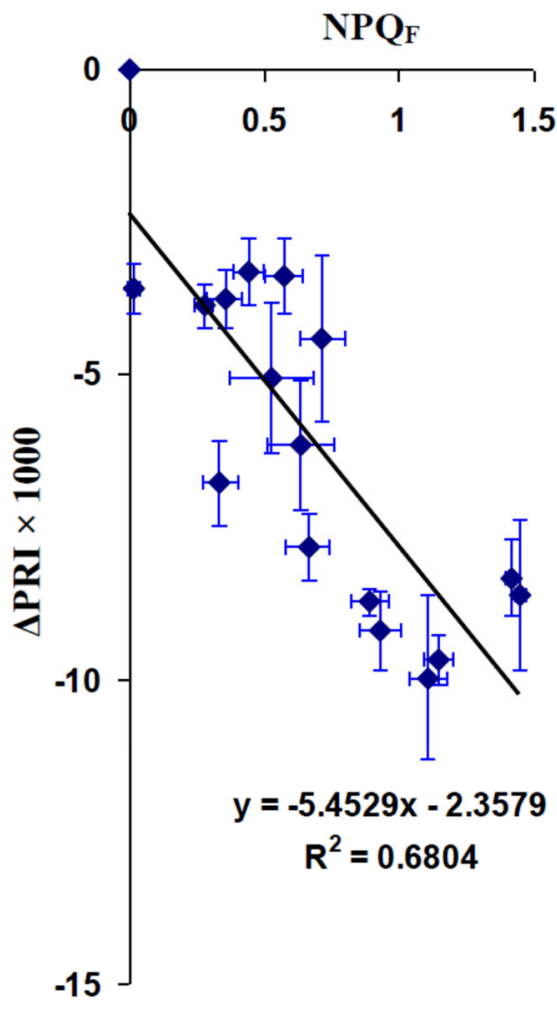

(b)

Figure 10. Scatter plots between $\mathrm{NPQ}_{\mathrm{F}}$ and PRI (a) and between $\mathrm{NPQ}_{\mathrm{F}}$ and $\triangle \mathrm{PRI}(\mathbf{b})$ calculated on the basis of all experiments. $\mathrm{K}_{\text {total }}=4.9913$ and $\mathrm{K} \Delta_{\text {totql }}=-5.4529$ are linear regression coefficients in the plots (a) and (b), respectively Average values of parameters and standard errors from Figure 3 , Figure 5, and Figure 7 were used. $R^{2}$ is the determination coefficient. Bars show standard errors.

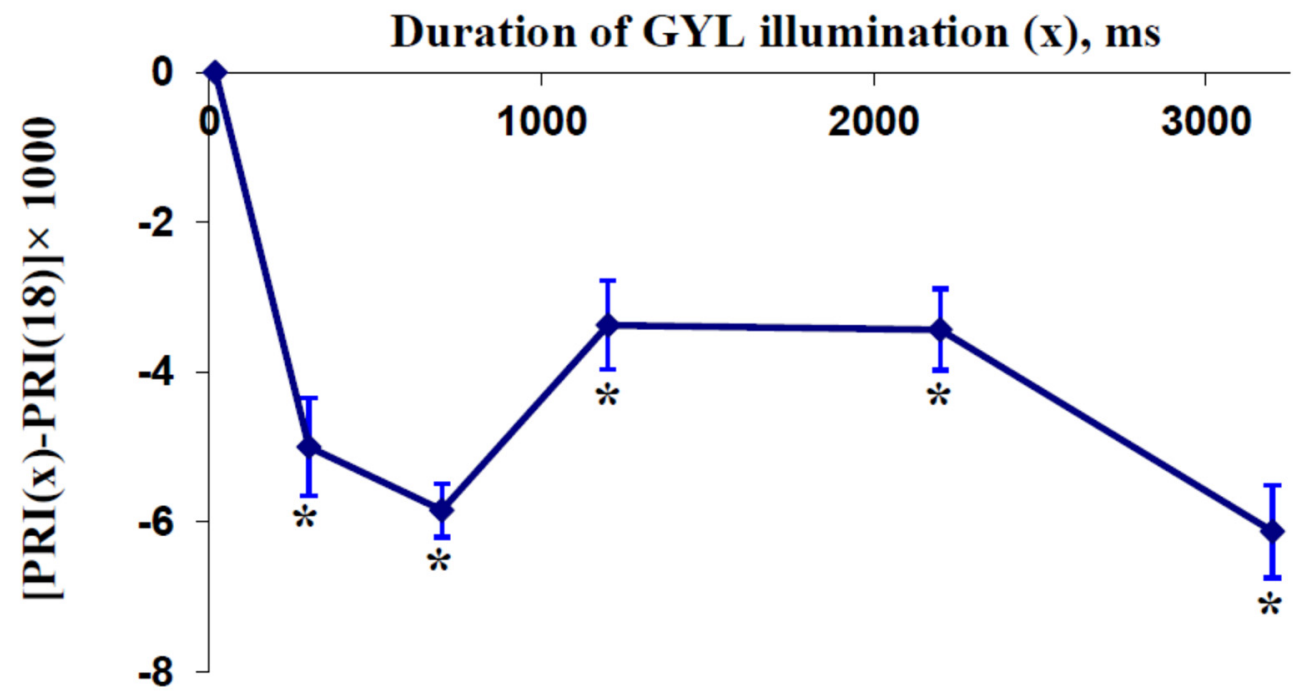

Figure 11. Dependence of green-yellow light (GYL)-induced changes in PRI on the duration of the illumination ( $n=8)$. GYL-induced changes were calculated as [PRI(x)-PRI(18)], where PRI(x) was PRI at the GYL illumination with duration equaling to $x$ ms and PRI(18) was PRI with the GYL illumination with duration equaling to $18 \mathrm{~ms}$. * indicates that [PRI(x)-PRI(18)] was significantly differed $(p<0.05)$ from $0 . n$ is number of repetitions. Bars show standard errors. 


\section{Discussion}

Measurement of intensities of reflected light at specific wavelengths and calculation of reflectance indices are the widely used methods of plant remote and proximal sensing which can be implemented for estimation of changes in their physiological processes [2-22] including photosynthesis [2-5]. Particularly, the photochemical reflectance index [32-35] can be sensitive to early photosynthetic changes under action of environmental stressors because PRI can change within minutes and, even, seconds after initiation of action of an adverse factor [32,37-41,54].

Mechanisms of fast changes in PRI are related to the de-epoxidation of violaxanthin to zeaxanthin via antheraxanthin through changes in absorption of green light $[32,37,46,47]$ and induction of light scattering at 530-546 nm [40,41], which, probably, can be induced by chloroplast shrinkage [38]. Both processes are caused by acidification of the chloroplast lumen due to photosynthetic electron transport chain activity [32,37,38,40,46,47]. The tight relation between induction of the fast changes in PRI and changes in $\mathrm{pH}$ may be basis of PRI sensitivity to photosynthetic processes. Particularly, the energy-dependent component of the non-photochemical quenching of chlorophyll fluorescence $\left(\mathrm{NPQ}_{\mathrm{F}}\right)$ is induced by the lumen acidification [42-44], which is often the result of action of excess light (through stimulation of activity of photosynthetic light reactions) or other stressors (through decrease of activity of photosynthetic dark reactions). The lumen acidification induces disruption of light energy transition in the light-harvesting complex that is caused by protonation of PsbS proteins $[55,56]$ and synthesis of zeaxanthin and anteraxanthin from violaxanthin in the xanthophyll cycle [57]; cooperative influence of these processes is also probable. It means that the non-photochemical quenching and, especially, $\mathrm{NPQ}_{\mathrm{F}}$ should be strongly related to PRI changes.

However, our meta-analysis [35] shows that the relation of the non-photochemical quenching to PRI can be strongly varied under sunlight, however using artificial illumination increases correlations between the parameters. Additionally, our previous results demonstrate that light-induced changes in PRI $(\triangle \mathrm{PRI})$ are more sensitive to the nonphotochemical quenching than absolute value of PRI [36,41,45]. The results show that measuring PRI with using artificial illumination under different light conditions, which is necessary for $\triangle \mathrm{PRI}$ estimation, is an important problem for remote and proximal plant photosynthetic sensing. Earlier, we proposed the method of PRI measuring with using pulses of green-yellow light and calculating differences between intensities of reflected light with GYL pulses and without ones [41]. It was shown [41] that PRI and $\triangle$ PRI can be correctly measured under illumination with different light intensities on the basis of this method and can be used for estimation of $\mathrm{NPQ}_{\mathrm{F}}$ in plant leaves.

The first result of the current study is the development of a system for proximal imaging of photosynthetic stress changes in plants using the proposed method [41] based on active illumination of leaves by short-term measuring pulses by GYL. It should be noted that using short-term GYL pulses is similar to the pulse-amplitude-modulation (PAM) method of fluorescence measurement, which is based on weak pulses of the measuring light and measurements of differences in the intensity of fluorescence during and before a pulse $[43,58]$. Application of GYL pulses minimizes influence of different intensities of background light and allows to measure PRI under different additional illumination of plants without calibration of the reflected light for each intensity of illumination. This is the basic feature of the developed setup which distinguishes it from the systems for PRI measurements using continuous artificial light or sunlight (e.g., $[52,53,59])$ that require periodic calibration.

Our previously developed modality of PRI measurements [36,41] was based on 30 s GYL pulses which could influence PRI because the fast component of changes in the photochemical reflectance indices is formed within a few seconds or less [38]. In contrast, the newly reported system can generate both short-term GYL pulses $(18 \mathrm{~ms})$, which are significantly shorter than the durations of all potential mechanisms of the PRI changes [34,36,38], and pulses with controlled durations, which induce fast changes in PRI. The property increases the 
efficiency of proximal imaging of photosynthetic processes in plants with the use of the developed system (e.g., the fast component of PRI changes can be measured or excluded from measurements).

Second, measurements of PRI, $\triangle \mathrm{PRI}$, and $\mathrm{NPQ}_{\mathrm{F}}$ under different light intensities (Figure 4), water shortage (Figure 6) and heating (Figure 8) show that changes in the parameters are similar to the changes revealed in our previous studies with using spectrometer as a point detector of reflected light $[41,45]$. $\triangle \mathrm{PRI}$ are strongly linearly related to $\mathrm{NPQ}_{\mathrm{F}}$ (Figures 5, 7 and 9) under actions of all investigated factors (light intensity, water shortage, and heating); moreover, the scatter plot based on all investigated experimental points (Figure 10) also shows strong linear dependence of $\triangle \mathrm{PRI}$ on $\mathrm{NPQ}_{\mathrm{F}}$. Linear regression coefficients $\left(\mathrm{K}_{\mathrm{I}}, \mathrm{K} \Delta_{\mathrm{I}}, \mathrm{K}_{\mathrm{W}}, \mathrm{K} \Delta_{\mathrm{W}}, \mathrm{K}_{\mathrm{H}}, \mathrm{K} \Delta_{\mathrm{H}}, \mathrm{K}_{\text {total }}, \mathrm{K} \Delta_{\text {total, }}\right.$ ) are similar to those parameters obtained in our previous studies [41,45]. The result shows that $\triangle \mathrm{PRI}$ obtained with the developed system can be used for proximal estimation (at the distances of about $50 \mathrm{~cm}$ ) of $\mathrm{NPQ}_{\mathrm{F}}$ which is strongly related to photosynthetic stress changes $[42-44,58]$. In contrast, the scatter plot based on all investigated experimental points of averaged absolute values of PRI and the energy-dependent component of the non-photochemical quenching (Figure 10) shows only weak linear dependence of PRI on $\mathrm{NPQ}_{\mathrm{F}}$ that is in a good accordance to our previous results $[41,45]$.

Differences in relations of PRI and $\triangle \mathrm{PRI}$ to $\mathrm{NPQ}_{\mathrm{F}}$ can be caused by their different mechanisms. Light-induced changes in PRI are mainly caused by fast acidification of the chloroplast lumen due to photosynthetic light reactions [32,37,38,40,41,46,47]; the acidification induces changes in absorption of green light and light scattering at 530-546 nm for minutes or even seconds. In contrast, absolute value of PRI can be additionally affected by long-term processes including modifications of carotenoid/chlorophyll pigment ratios and the total xanthophyll pigment pool size [13,48-51] which also modify absorption of green light. As a result, (i) absolute values of PRI should be characterized by the increased standard errors in comparison with SEs of $\triangle$ PRI because separate plants can have individual variability in the long-term processes influencing PRI. Our current results (SEs were 1.6-4.9 for PRI $\times 1000$ and $0.2-1.4$ for $\Delta \mathrm{PRI} \times 1000$, Figures 4,6 and 8 ) and literature data [41,45] show the difference between standard errors and support this point. (ii) Probably the increase of duration of stressor action can modify relations of PRI to $\mathrm{NPQ}_{\mathrm{F}}$ and should weakly influence relations of $\triangle \mathrm{PRI}$ to $\mathrm{NPQ}_{\mathrm{F}}$ due to long-term physiological processes effecting the absolute value of PRI. Our results confirm the last point because dependence of $\triangle \mathrm{PRI}$ on $\mathrm{NPQ}_{\mathrm{F}}$ under the short-term action of illumination with different intensities (minutes, Figure $5 b$ ) is similar to the dependence under the long-term water shortage (days, Figure $7 \mathrm{~b}$ ). In contrast, dependence of $\mathrm{PRI}$ on $\mathrm{NPQ}_{\mathrm{F}}$ under the short-term action of illumination (Figure 5a) is strongly differed from the dependence under the longterm water shortage (Figure 7a). The results are in a good accordance with our previous data $[41,45]$ showing different dependences of PRI on $\mathrm{NPQ}_{\mathrm{F}}$ and similar dependences of $\triangle \mathrm{PRI}$ on $\mathrm{NPQ}_{\mathrm{F}}$ under action of stressors with different durations. Literature data additionally confirm higher efficiency of light-induced changes in PRI for estimation of photosynthetic processes in comparison to absolute value of PRI [60,61].

Third, we show short-term changes in PRI (hundreds of milliseconds and seconds) induced by illumination (Figure 11). The result confirms a hypothesis by Evain et al. [38] on the possibility of changes in PRI with duration less than several seconds. Changes in the light scattering at $530-546 \mathrm{~nm}$ which are caused by illumination (including light with weak intensity [62]) and following chloroplast lumen acidification [63-65] and modifies the leaf light absorbance [66-68] are potential mechanism of PRI changes in ranges of seconds and minutes $[36,40]$. It is known $[40,65]$ that the first component of the changes in the light scattering under illumination is extremely fast (less than several seconds) and potentially related to electrochromic pigment absorbance shift which is caused by forming electrical potential gradient across thylakoid membranes $[65,69,70]$. Considering these facts, we hypothesize that the electrochromic shift can participate in the fast changes in PRI. The electrochromic shift is only partially related to changes in the stromal and luminal 
$\mathrm{pH}[65,70]$; it can explain the component of light-induced PRI changes, which are weakly related to $\mathrm{NPQ}_{\mathrm{F}}$ (Figure 5 and Figure S2).

Thus, the developed system of proximal PRI imaging on the basis of short-term measuring pulses of GYL can be used for continuous measurements of PRI and $\triangle \mathrm{PRI}$ in broad time range (hundreds of milliseconds, seconds, or minutes). The measurements are the basis for estimation of photosynthetic changes in plant leaves under stressors action (e.g., the excess light, water shortage, and heating) or for analysis of mechanisms of fast changes in PRI and their relations to photosynthetic processes. It should be noted that this stage of analysis of efficiency of the developed system included laboratory investigations of leaves which had fixed positions in the same plane, i.e., we did not estimate the efficiency of the system for the analysis of PRI in plant canopy (field or greenhouse) or group of plants which had not fixed position of leaves (vegetation pot). Additionally, we did not analyze the influence of stressors on spatial distribution of PRI and $\triangle \mathrm{PRI}$ in leaves and whole plants. Finally, it is not clear: can the fast changes in PRI be used for proximal photosynthetic sensing? The mentioned points are important tasks of future analysis.

\section{Conclusions}

A novel system of proximal PRI imaging on the basis of short-term measuring pulses of green-yellow light has been developed. Its efficiency was primarily evaluated with using pea seedlings in laboratory experiments. The system measured absolute values and light-induced changes in PRI which were sensitive to actions of illumination with different light intensities, water shortage, and heating. $\triangle \mathrm{PRI}$ was linearly dependent on the energydependent component of the non-photochemical quenching under action of all investigated stressors; i.e., the system can be used for proximal early revealing photosynthetic stress changes. Additionally, the system demonstrated the fast changes in PRI under illumination by green-yellow light for about $3 \mathrm{~s}$. The possibility of measuring fast changes in PRI can be important for revealing mechanisms of the photochemical reflectance index forming and searching new tools of proximal sensing of plant photosynthetic processes on basis of PRI measurements.

Thus, the system shows that it can be potentially perspective for developing photosynthetic remote sensing in greenhouses and, probably, fields in future. However, there are several important tasks for future analysis. The first task is the investigation of efficiency of PRI measuring in plant canopy or groups of plants which do not have fixed positions of leaves. The second task is investigation of influence of stressors on spatial distribution of PRI and $\triangle \mathrm{PRI}$ in leaves and whole plants. The third task is the analysis of mechanisms of the fast changes in PRI and estimation of their perspectives for proximal sensing.

Supplementary Materials: The following are available online at https://www.mdpi.com/article/ 10.3390/rs13091762/s1, Figure S1: Spectrum of green-yellow light of light-emitting diodes and spectra of light transmission of single-band bandpass filter FF01-530/11, single-band bandpass filter FF01-575/15, and beamsplitter FF552-Di02, Figure S2: Scatter plots between NPQ and PRI and between $\mathrm{NPQ}_{\mathrm{F}}$ and $\triangle \mathrm{PRI}$ in experiments with actions of ALs with different intensities excluding the point with zero illumination by actinic light, Figure S3: Scatter plots between $\mathrm{NPQ}_{\mathrm{F}}$ and PRI (a) and between $\mathrm{NPQ}_{\mathrm{F}}$ and $\triangle \mathrm{PRI}(\mathrm{b})$ in experiments with actions of ALs with different intensities, Figure S4: The dependence of relative water content in pea leaves on duration of water shortage, Figure S5: Scatter plots between $\mathrm{NPQ}_{\mathrm{F}}$ and PRI (a) and between $\mathrm{NPQ}_{\mathrm{F}}$ and $\triangle \mathrm{PRI}$ (b) in experiments with water shortage, Figure S6: Scatter plots between $\mathrm{NPQ}_{\mathrm{F}}$ and PRI (a) and between $\mathrm{NPQ}_{\mathrm{F}}$ and $\triangle \mathrm{PRI}$ (b) in experiments with heating, Figure S7: Scatter plots between $\mathrm{NPQ}_{\mathrm{F}}$ and PRI (a) and between $\mathrm{NPQ}_{\mathrm{F}}$ and $\triangle \mathrm{PRI}(\mathrm{b})$ calculated on basis of all experiments.

Author Contributions: Conceptualization, V.S., V.V. and I.T.; methodology, V.S., E.S.( Ekaterina Sukhova) and E.S.(Ekaterina Sergeeva); software, A.T.; formal analysis, V.S., E.S.(Ekaterina Sukhova), A.K. and A.R.; investigation, A.K., L.Y., A.R., A.T. and E.S.(Ekaterina Sergeeva); resources, I.T.; writing — original draft preparation, V.S. and E.S.(Ekaterina Sukhova); writing—review and editing, V.S., E.S. (Ekaterina Sergeeva) and I.T.; supervision, V.S.; project administration, V.S., V.V. and I.T.; funding acquisition, V.S. All authors have read and agreed to the published version of the manuscript. 
Funding: This research was funded by funded by the Russian Science Foundation, grant number 17-76-20032.

Institutional Review Board Statement: Not applicable.

Informed Consent Statement: Not applicable.

Data Availability Statement: The data presented in this study are available on request from the corresponding author.

Acknowledgments: The authors are grateful to electrical engineer Vladimir Vorob'ev for design and creation of electrical part of the imaging system, and mechanical engineer Sergey Pozhidaev for creation mechanical parts of the imaging system.

Conflicts of Interest: The authors declare no conflict of interest. The funders had no role in the design of the study; in the collection, analyses, or interpretation of data; in the writing of the manuscript, or in the decision to publish the results.

\section{References}

1. Pinter, P.J., Jr.; Hatfield, J.L.; Schepers, J.S.; Barnes, E.M.; Moran, M.S.; Daughtry, C.S.T.; Upchurch, D.R. Remote sensing for crop management. Photogram. Eng. Remote Sens. 2003, 69, 647-664. [CrossRef]

2. Grace, J.; Nichol, C.; Disney, M.; Lewis, P.; Quaife, T.; Bowyer, P. Can we measure terrestrial photosynthesis from space directly, using spectral reflectance and fluorescence? Glob. Chang. Biol. 2007, 13, 1484-1497. [CrossRef]

3. Peñuelas, J.; Garbulsky, M.F.; Filella, I. Photochemical reflectance index (PRI) and remote sensing of plant $\mathrm{CO}_{2}$ uptake. New Phytol. 2011, 191, 596-599. [CrossRef] [PubMed]

4. Weng, J.H.; Wong, S.L.; Lai, K.M.; Lin, R.J. Relationships between photosystem II efficiency and photochemical reflectance index under different levels of illumination: Comparison among species grown at high- and low elevations through different seasons. Trees-Struct. Funct. 2012, 26, 343-351. [CrossRef]

5. Zhang, C.; Filella, I.; Liu, D.; Ogaya, R.; Llusià, J.; Asensio, D.; Peñuelas, J. Photochemical reflectance index (PRI) for detecting responses of diurnal and seasonal photosynthetic activity to experimental drought and warming in a mediterranean shrubland. Remote Sens. 2017, 9, 1189. [CrossRef]

6. Peñuelas, J.; Filella, I.; Biel, C.; Serrano, L.; Savé, R. The reflectance at the 950-970 nm region as an indicator of plant water status. Int. J. Remote Sens. 1993, 14, 1887-1905. [CrossRef]

7. Peñuelas, J.; Piñol, J.; Ogaya, R.; Filella, I. Estimation of plant water concentration by the reflectance Water Index WI (R900/R970). Int. J. Remote Sens. 1997, 18, 2869-2875. [CrossRef]

8. Gitelson, A.; Merzlyak, M.N. Spectral reflectance changes associated with autumn senescence of Aesculus hippocastanum L. and Acer platanoides L. leaves. Spectral features and relation to chlorophyll estimation. Plant Physiol. 1994, 143, 286-292. [CrossRef]

9. Blackburn, G.A. Quantifying chlorophylls and carotenoids at leaf and canopy scale: An evaluation of some hyperspectral approaches. Remote Sens. Environ. 1998, 66, 273-285. [CrossRef]

10. Gamon, J.A.; Huemmrich, K.F.; Wong, C.Y.S.; Ensminger, I.; Garrity, S.; Hollinger, D.Y.; Noormets, A.; Peñuelas, J. A remotely sensed pigment index reveals photosynthetic phenology in evergreen conifers. Proc. Natl. Acad. Sci. USA 2016, 113, 13087-13092. [CrossRef]

11. Penuelas, J.; Baret, F.; Filella, I. Semiempirical indices to assess carotenoids/chlorophyll a ratio from leaf spectral reflectance. Photosynthetica 1995, 31, 221-230.

12. Filella, I.; Amaro, T.; Araus, J.L.; Peñuelas, J. Relationship between photosynthetic radiation-use efficiency of barley canopies and the photochemical reflectance index (PRI). Physiol. Plant 1996, 96, 211-216. [CrossRef]

13. Filella, I.; Porcar-Castell, A.; Munné-Bosch, S.; Bäck, J.; Garbulsky, M.F.; Peñuelas, J. PRI assessment of long-term changes in carotenoids/chlorophyll ratio and short-term changes in de-epoxidation state of the xanthophyll cycle. Int. J. Remote Sens. 2009, 30, 4443-4455. [CrossRef]

14. Peñuelas, J.; Marino, G.; Llusia, J.; Morfopoulos, C.; Farré-Armengol, G.; Filella, I. Photochemical reflectance index as an indirect estimator of foliar isoprenoid emissions at the ecosystem level. Nat. Commun. 2013, 4, 2604. [CrossRef]

15. Balzarolo, M.; Peñuelas, J.; Filella, I.; Portillo-Estrada, M.; Ceulemans, R. Assessing ecosystem isoprene emissions by hyperspectral remote sensing. Remote Sens. 2018, 10, 1086. [CrossRef]

16. Sukhov, V.; Sukhova, E.; Gromova, E.; Surova, L.; Nerush, V.; Vodeneev, V. The electrical signal-induced systemic photosynthetic response is accompanied by changes in the photochemical reflectance index in pea. Funct. Plant Biol. 2019, 46, 328-338. [CrossRef] [PubMed]

17. Sukhova, E.; Yudina, L.; Akinchits, E.; Vodeneev, V.; Sukhov, V. Influence of electrical signals on pea leaf reflectance in the 400-800-nm range. Plant Signal. Behav. 2019, 14, 1610301. [CrossRef]

18. Sukhova, E.; Yudina, L.; Gromova, E.; Nerush, V.; Vodeneev, V.; Sukhov, V. Burning-induced electrical signals influence broadband reflectance indices and water index in pea leaves. Plant Signal. Behav. 2020, 15, 1737786. [CrossRef] 
19. Mahlein, A.K.; Steiner, U.; Dehne, H.W.; Oerke, E.C. Spectral signatures of sugar beet leaves for the detection and differentiation of diseases. Precis. Agric. 2010, 11, 413-431. [CrossRef]

20. Mahlein, A.-K. Plant disease detection by imaging sensors-parallels and specific demands for precision agriculture and plant phenotyping. Plant Dis. 2016, 100, 241-251. [CrossRef]

21. Mahlein, A.K.; Kuska, M.T.; Behmann, J.; Polder, G.; Walter, A. Hyperspectral sensors and imaging technologies in phytopathology: State of the art. Annu. Rev. Phytopathol. 2018, 56, 535-558. [CrossRef] [PubMed]

22. Badgley, G.; Field, C.B.; Berry, J.A. Canopy near-infrared reflectance and terrestrial photosynthesis. Sci. Adv. 2017, 3, e1602244. [CrossRef] [PubMed]

23. Rouse, J.W., Jr.; Haas, R.H.; Schell, J.A.; Deering, D.W.; Harlan, J.C. Monitoring the Vernal Advancement and Retrogradation (Green Wave Effect) of Natural Vegetation; Type III Final Rep; The National Aeronautics and Space Administration (NASA)/Goddard Space Flight Center (GSFC): Greenbelt, MD, USA, 1974.

24. Eitel, J.U.H.; Long, D.S.; Gessler, P.E.; Hunt, E.R., Jr.; Brown, D.J. Sensitivity of ground-based remote sensing estimates of wheat chlorophyll content to variation in soil reflectance. Soil Sci. Soc. Am. J. 2009, 73, 1715-1723. [CrossRef]

25. Gao, B.C. NDWI-A normalized difference water index for remote sensing of vegetation liquid water from space. Remote Sens. Environ. 1996, 158, 257-266. [CrossRef]

26. Sytar, O.; Brücková, K.; Kovár, M.; Živčák, M.; Hemmerich, I.; Brestič, M. Nondestructive detection and biochemical quantification of buckwheat leaves using visible (VIS) and near-infrared (NIR) hyperspectral reflectance imaging. J. Centr. Eur. Agric. 2017, 18, 864-878. [CrossRef]

27. Kovar, M.; Brestic, M.; Sytar, O.; Barek, V.; Hauptvogel, P.; Zivcak, M. Evaluation of hyperspectral reflectance parameters to assess the leaf water content in soybean. Water 2019, 11, 443. [CrossRef]

28. El-Hendawy, S.; Al-Suhaibani, N.; Dewir, Y.H.; Elsayed, S.; Alotaibi, M.; Hassan, W.; Refay, Y.; Tahir, M.U. Ability of modified spectral reflectance indices for estimating growth and photosynthetic efficiency of wheat under saline field conditions. Agronomy 2019, 9, 35. [CrossRef]

29. El-Hendawy, S.E.; Alotaibi, M.; Al-Suhaibani, N.; Al-Gaadi, K.; Hassan, W.; Dewir, Y.H.; Emam, M.A.E.-G.; Elsayed, S.; Schmidhalter, U. Comparative performance of spectral reflectance indices and multivariate modeling for assessing agronomic parameters in advanced spring wheat lines under two contrasting irrigation regimes. Front. Plant Sci. 2019, 10, 1537. [CrossRef]

30. Sun, H.; Feng, M.; Xiao, L.; Yang, W.; Wang, C.; Jia, X.; Zhao, Y.; Zhao, C.; Muhammad, S.K.; Li, D. Assessment of plant water status in winter wheat (Triticum aestivum L.) based on canopy spectral indices. PLoS ONE 2019, 14, e0216890. [CrossRef]

31. Sukhova, E.; Yudina, L.; Gromova, E.; Ryabkova, A.; Kior, D.; Sukhov, V. Complex analysis of the efficiency of difference reflectance indices on the basis of 400-700 nm wavelengths for revealing the influences of water shortage and heating on plant seedlings. Remote Sens. 2021, 13, 962. [CrossRef]

32. Gamon, J.A.; Peñuelas, J.; Field, C.B. A narrow-waveband spectral index that tracks diurnal changes in photosynthetic efficiency. Remote Sens. Environ. 1992, 41, 35-44. [CrossRef]

33. Garbulsky, M.F.; Peñuelas, J.; Gamon, J.; Inoue, Y.; Filella, I. The photochemical reflectance index (PRI) and the remote sensing of leaf, canopy and ecosystem radiation use efficiencies. A review and meta-analysis. Remote Sens. Environ. 2011, 115, 281-297. [CrossRef]

34. Zhang, C.; Filella, I.; Garbulsky, M.F.; Peñuelas, J. Affecting factors and recent improvements of the photochemical reflectance index (PRI) for remotely sensing foliar, canopy and ecosystemic radiation-use efficiencies. Remote Sens. 2016, 8, 677. [CrossRef]

35. Sukhova, E.; Sukhov, V. Connection of the photochemical reflectance index (PRI) with the photosystem II quantum yield and nonphotochemical quenching can be dependent on variations of photosynthetic parameters among investigated plants: A meta-analysis. Remote Sens. 2018, 10, 771. [CrossRef]

36. Sukhova, E.; Sukhov, V. Relation of photochemical reflectance indices based on different wavelengths to the parameters of light reactions in photosystems I and II in pea plants. Remote Sens. 2020, 12, 1312. [CrossRef]

37. Peñuelas, J.; Filella, I.; Gamon, J.A. Assessment of photosynthetic radiation-use efficiency with spectral reflectance. New Phytol. 1995, 131, 291-296. [CrossRef]

38. Evain, S.; Flexas, J.; Moya, I. A new instrument for passive remote sensing: 2. Measurement of leaf and canopy reflectance changes at $531 \mathrm{~nm}$ and their relationship with photosynthesis and chlorophyll fluorescence. Remote Sens. Environ. 2004, 91, 175-185. [CrossRef]

39. Murakami, K.; Ibaraki, Y. Time course of the photochemical reflectance index during photosynthetic induction: Its relationship with the photochemical yield of photosystem II. Physiol. Plant 2019, 165, 524-536. [CrossRef]

40. Sukhova, E.M.; Yudina, L.M.; Vodeneev, V.A.; Sukhov, V.S. Analysis of changes in photochemical reflectance index (PRI) in relation to the acidification of the lumen of the chloroplasts of pea and geranium leaves under a short-term illumination. Biochem. Moscow. Suppl. Ser. A 2019, 13, 243-252. [CrossRef]

41. Sukhova, E.; Sukhov, V. Analysis of light-induced changes in the photochemical reflectance index (PRI) in leaves of pea, wheat, and pumpkin using pulses of green-yellow measuring light. Remote Sens. 2019, 11, 810. [CrossRef]

42. Maxwell, K.; Johnson, G.N. Chlorophyll fluorescence-A practical guide. J. Exp. Bot. 2000, 51, 659-668. [CrossRef]

43. Porcar-Castell, A.; Tyystjärvi, E.; Atherton, J.; van der Tol, C.; Flexas, J.; Pfündel, E.E.; Moreno, J.; Frankenberg, C.; Berry, J.A. Linking chlorophyll a fluorescence to photosynthesis for remote sensing applications: Mechanisms and challenges. J. Exp. Bot. 2014, 65, 4065-4095. [CrossRef] [PubMed] 
44. Ruban, A.V. Nonphotochemical chlorophyll fluorescence quenching: Mechanism and effectiveness in protecting plants from photodamage. Plant Physiol. 2016, 170, 1903-1916. [CrossRef]

45. Yudina, L.; Sukhova, E.; Gromova, E.; Nerush, V.; Vodeneev, V.; Sukhov, V. A light-induced decrease in the photochemical reflectance index (PRI) can be used to estimate the energy-dependent component of non-photochemical quenching under heat stress and soil drought in pea, wheat, and pumpkin. Photosynth. Res. 2020, 146, 175-187. [CrossRef]

46. Gamon, J.A.; Field, C.B.; Bilger, W.; Björkman, O.; Fredeen, A.L.; Peñuelas, J. Remote sensing of the xanthophyll cycle and chlorophyll fluorescence in sunflower leaves and canopies. Oecologia 1990, 85, 1-7. [CrossRef] [PubMed]

47. Kohzuma, K.; Hikosaka, K. Physiological validation of photochemical reflectance index (PRI) as a photosynthetic parameter using Arabidopsis thaliana mutants. Biochem. Biophys. Res. Commun. 2018, 498, 52-57. [CrossRef]

48. Porcar-Castell, A.; Garcia-Plazaola, J.I.; Nichol, C.J.; Kolari, P.; Olascoaga, B.; Kuusinen, N.; Fernández-Marín, B.; Pulkkinen, M.; Juurola, E.; Nikinmaa, E. Physiology of the seasonal relationship between the photochemical reflectance index and photosynthetic light use efficiency. Oecologia 2012, 170, 313-323. [CrossRef]

49. Stylinski, C.D.; Gamon, J.A.; Oechel, W.C. Seasonal patterns of reflectance indices, carotenoid pigments and photosynthesis of evergreen chaparral species. Oecologia 2002, 131, 366-374. [CrossRef] [PubMed]

50. Garbulsky, M.F.; Peñuelas, J.; Ogaya, R.; Filella, I. Leaf and stand-level carbon uptake of a Mediterranean forest estimated using the satellite-derived reflectance indices EVI and PRI. Int. J. Remote Sens. 2013, 34, 1282-1296. [CrossRef]

51. Wong, C.Y.; Gamon, J.A. Three causes of variation in the photochemical reflectance index (PRI) in evergreen conifers. New Phytol. 2015, 206, 187-195. [CrossRef]

52. Ibaraki, Y.; Dutta Gupta, S. Nondestructive evaluation of the photosynthetic properties of micropropagated plantlets by imaging photochemical reflectance index under low light intensity. Vitr. Cell. Dev. Biol. Plant 2010, 46, 530-536. [CrossRef]

53. Ibaraki, Y.; Matsumura, K.; Dutta Gupta, D. Low-cost photochemical reflectance index measurements of micropropagated plantlets using image analysis. Comput. Electron. Agric. 2010, 71, 170-175. [CrossRef]

54. Gamon, J.A.; Surfus, J.S. Assessing leaf pigment content and activity with a reflectometer. New Phytol. 1999, 143, 105-117. [CrossRef]

55. Li, X.P.; Björkman, O.; Shih, C.; Grossman, A.R.; Rosenquist, M.; Jansson, S.; Niyogi, K.K. A pigment-binding protein essential for regulation of photosynthetic light harvesting. Nature. 2000, 403, 391-395. [CrossRef] [PubMed]

56. Jajoo, A.; Mekala, N.R.; Tongra, T.; Tiwari, A.; Grieco, M.; Tikkanen, M.; Aro, E.M. Low pH-induced regulation of excitation energy between the two photosystems. FEBS Lett. 2014, 588, 970-974. [CrossRef]

57. Demmig-Adams, B.; Adams III, W.W. The role of xanthophyll cycle carotenoids in the protection of photosynthesis. Trends Plant Sci. 1996, 1, 21-26. [CrossRef]

58. Kalaji, H.M.; Schansker, G.; Ladle, R.J.; Goltsev, V.; Bosa, K.; Allakhverdiev, S.I.; Brestic, M.; Bussotti, F.; Calatayud, A.; Dabrowski, P.; et al. Frequently asked questions about in vivo chlorophyll fluorescence: Practical issues. Photosynth. Res. 2014, 122, 121-158. [CrossRef] [PubMed]

59. Magney, T.S.; Eusden, S.A.; Eitel, J.U.H.; Logan, B.A.; Jiang, J.; Vierling, L.A. Assessing leaf photoprotective mechanisms using terrestrial LiDAR: Towards mapping canopy photosynthetic performance in three dimensions. New Phytol. 2014, 201, 344-356. [CrossRef]

60. Kováč, D.; Veselovská, P.; Klem, K.; Večeřová, K.; Ač, A.; Peñuelas, J.; Urban, O. Potential of photochemical reflectance index for indicating photochemistry and light use efficiency in leaves of European beech and Norway spruce trees. Remote Sens. 2018, 10, 1202. [CrossRef]

61. Kováč, D.; Veselá, B.; Klem, K.; Večeřová, K.; Kmecová, Z.M.; Peñuelas, J.; Urban, O. Correction of PRI for carotenoid pigment pools improves photosynthesis estimation across different irradiance and temperature conditions. Remote Sens. Environ. 2020, 244, 111834. [CrossRef]

62. Gamon, J.A.; Serrano, L.; Surfus, J.S. The photochemical reflectance index: An optical indicator of photosynthetic radiation use efficiency across species, functional types, and nutrient levels. Oecologia. 1997, 112, 492-501. [CrossRef]

63. Deamer, D.W.; Crofts, A.R.; Packer, L. Mechanisms of light-induced structural changes in chloroplasts I. Light-scattering increments and ultrastructural changes mediated by proton transport. Biochim. Biophys. Acta. 1967, 131, 81-96. [CrossRef]

64. Murakami, S.; Packer, L. Protonation and chloroplast membrane structure. J. Cell Biol. 1970, 47, 332-351. [CrossRef]

65. Schreiber, U.; Klughammer, C. New accessory for the DUAL-PAM-100: The P515/535 module and examples of its application. PAM Appl. Notes 2008, 1, 1-10.

66. Bilger, W.; Björkman, O.; Thayer, S.S. Light-induced spectral absorbance changes in relation to photosynthesis and the epoxidation state of xanthophyll cycle components in cotton leaves. Plant Physiol. 1989, 91, 542-551. [CrossRef]

67. Bilger, W.; Björkman, O. Relationships among violaxanthin deepoxidation, thylakoid membrane conformation, and nonphotochemical chlorophyll fluorescence quenching in leaves of cotton (Gossypium hirsutum L.). Planta 1994, 193, 238-246. [CrossRef]

68. Van Wittenberghe, S.; Alonso, L.; Malenovský, Z.; Moreno, J. In vivo photoprotection mechanisms observed from leaf spectral absorbance changes showing VIS-NIR slow-induced conformational pigment bed changes. Photosynth. Res. 2019, 142, 283-305. [CrossRef]

69. Avenson, T.J.; Cruz, J.A.; Kramer, D.M. Modulation of energy-dependent quenching of excitons in antennae of higher plants. Proc. Natl. Acad. Sci. USA 2004, 101, 5530-5535. [CrossRef] [PubMed]

70. Klughammer, C.; Siebke, K.; Schreiber, U. Continuous ECS-indicated recording of the proton-motive charge flux in leaves. Photosynth. Res. 2013, 117, 471-487. [CrossRef] [PubMed] 